This item was submitted to Loughborough's Research Repository by the author.

Items in Figshare are protected by copyright, with all rights reserved, unless otherwise indicated.

\title{
Watch out for the hazard! Blurring peripheral vision facilitates hazard perception in driving
}

PLEASE CITE THE PUBLISHED VERSION

https://doi.org/10.1016/j.aap.2020.105755

\section{PUBLISHER}

Elsevier

VERSION

AM (Accepted Manuscript)

\section{PUBLISHER STATEMENT}

This paper was accepted for publication in the journal Accident Analysis and Prevention and the definitive published version is available at https://doi.org/10.1016/j.aap.2020.105755.

LICENCE

CC BY-NC-ND 4.0

\section{REPOSITORY RECORD}

Ryu, Donghyun, Andrew Cooke, Eduardo Bellomo, and Tim Woodman. 2020. "Watch Out for the Hazard! Blurring Peripheral Vision Facilitates Hazard Perception in Driving”. Loughborough University. https://hdl.handle.net/2134/13234364.v1. 
Running Head: HAZARD PERCEPTION AND VISION

Watch out for the hazard! Blurring peripheral vision facilitates hazard perception in driving

Donghyun Ryu ${ }^{\mathrm{a}, \mathrm{b}}$, Andrew Cooke $^{\mathrm{b}}$, Eduardo Bellomo $^{\mathrm{b}}$, \& Tim Woodman ${ }^{\mathrm{b}}$

aSchool of Sport, Exercise and Health Sciences, Loughborough University, Loughborough,

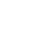
United Kingdom

${ }^{\mathrm{b}}$ School of Sport, Health \& Exercise Sciences, Bangor University, Bangor, United Kingdom 8

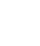

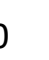

1

2

3


1 Author notes:

2 Donghyun Ryu was supported by an AXA Research Fellowship (16-AXA-PDOC-013)

3 awarded by the AXA Research Fund. Portions of the data have been previously presented at

4 the $23^{\text {rd }}$ Annual Congress of The European College of Sport Science and in a published

5 abstract titled, "Watch out for the Hazard! Blurring peripheral vision facilitates hazard

6 perception in driving”. Donghyun Ryu: Conceptualization, Data curation, Formal analysis,

7 Funding acquisition, Investigation, Methodology, Project administration, Validation,

8 Visualization, Roles/Writing - original draft, Writing - Review \& Editing; Andrew Cooke:

9 Conceptualization, Funding acquisition, Methodology, Project administration, Roles/Writing

10 - original draft, Writing - Review \& Editing; Eduardo Bellomo: Data curation, Formal

11 analysis, Roles/Writing - original draft, Writing - Review \& Editing; Tim Woodman:

12 Conceptualization, Funding acquisition, Project administration, Roles/Writing - original draft,

13 Writing - Review \& Editing.

Address for correspondence:

21 Donghyun Ryu

22 School of Sport, Exercise and Health Sciences

23 Loughborough University

24 Epinal Way, Leicestershire

25 United Kingdom

26 LE11 3TU

27 Email: D.Ryu@1boro.ac.uk

28 Phone: +4401509226417 


\section{Abstract}

2 The objectives of this paper were to directly examine the roles of central and peripheral vision in hazard perception and to test whether perceptual training can enhance hazard perception. We also examined putative cortical mechanisms underpinning any effect of perceptual training on performance. To address these objectives, we used the gaze-contingent

6 display paradigm to selectively present information to central and peripheral parts of the visual field. In Experiment 1, we compared hazard perception abilities of experienced and inexperienced drivers while watching video clips in three different viewing conditions (full vision; clear central and blurred peripheral vision; blurred central and clear peripheral vision). Participants' visual search behaviour and cortical activity were simultaneously recorded. In Experiment 2, we determined whether training with clear central and blurred peripheral vision could improve hazard perception among non-licensed drivers. Results demonstrated that (i) information from central vision is more important than information from peripheral vision in identifying hazard situations, for screen-based hazard perception tests, (ii) clear central and blurred peripheral vision viewing helps the alignment of line-of-gaze and attention, (iii) training with clear central and blurred peripheral vision can improve screenbased hazard perception. The findings have important implications for road safety and provide a new training paradigm to improve hazard perception.

Key words: gaze-contingent display, hazard perception, attention, central vision, peripheral vision 


\section{Watch out for the hazard!}

\section{Blurring peripheral vision facilitates hazard perception in driving}

3

4

5

6

\section{Introduction}

In dynamic externally paced activities such as driving a vehicle and playing sport, selecting and integrating the most useful visual information promotes successful performance. Visual stimuli change very rapidly across the entire visual field when driving, so quickly recognizing and anticipating future hazards is crucial to decrease the risk of vehicle accidents (Underwood, Crundall, \& Chapman, 2008). Accordingly, investigations of the way drivers use their vision when faced with dynamic road scenes can provide important information about the mechanisms underpinning hazard perception and safe driving performance.

To understand the role of vision in driving, eye-tracking studies have demonstrated that experienced drivers fixate more distant locations while the fixations of novice drivers are generally confined to the section of road immediately in front of the vehicle. This contributes to inferior hazard detection in novice compared to experienced drivers (see Horswill \& McKenna, 2004, for a review). Researchers have also tested the visual field by measuring the ability of the visual system to process light presented to the retina at varying eccentricities, and examining the relationship between the visual field and driving safety (e.g., Huisingh, McGwin, Wood, \& Owsley, 2015; McLean, Mueller, Buttery, \& Mackey, 2002; Wood \& Troutbeck, 1992). For example, Huisingh et al. (2015) found that older drivers with severe impairments to their visual field (i.e., light sensitivity in the bottom quartile for their age group) were more likely to have a history of involvement in at-fault driving collisions than those without visual impairment. The useful field of view, which refers to the visual area from which information can be extracted in a single eye fixation and thereby indicates one's ability to pay attention to one's visual field, is also frequently explored in driving and road safety research (Ball, Beard, Roenker, Miller, \& Griggs, 1988; Crundall, Underwood, \& 
1 Chapman, 1999). For example, Ball, Owsley, Sloane, Roenker, and Bruni (1993) revealed

2 that the size of the useful field of view was associated with vehicle crash involvement risk;

3 older adults were more likely to be involved in a crash with a smaller useful field of view.

4 The useful field of view has also been applied in studies of experienced versus novice drivers.

5 For example, Crundall et al. (1999) revealed that novice drivers had little attentional capacity

6 to attend to peripheral visual information, as they required greater attentional resources to

7 concentrate on unfamiliar information from central vision (perceptual narrowing; Underwood

8 et al., 2008; Weltman \& Egstrom, 1966). This finding is important because hazards that we

9 must respond to while driving often first appear in our peripheral vision. As visual

10 information is continuously changing and critical events occur with little or no advance

11 warning in driving, the simultaneous use of central and peripheral vision seem essential for

12 safe driving.

\subsection{The distinct roles of central and peripheral vision in driving}

In general, peripheral vision plays a role in both quickly detecting movement and in guiding direction of future eye movements. In driving, peripheral vision is important for vehicle control in lane maintenance (Land \& Horwood, 1995) and risk/hazard detection (Chapman \& Underwood, 1998; Crundall et al., 1999). For example, if an imminent hazard is evident in the peripheral visual field (e.g., the unexpected emergence of a cyclist from a side street), drivers first need to detect the hazard using their peripheral vision, and then re-direct their central vision towards the hazard to extract detailed information and to assess the most appropriate response (Chapman \& Underwood, 1998; Crundall et al., 1999). Experienced drivers are better than novices at detecting risks with peripheral vision, and at re-directing central vision to the hazard (Crundall, Underwood, \& Chapman, 2002). However, these previous studies used eye-tracking to measure central vision via line-of-gaze and assessed peripheral vision indirectly by making inferences from awareness of peripheral stimuli. 
1 Fortunately, the interactions between central and peripheral vision can be assessed more

2 directly via the gaze-contingent display paradigm.

The gaze-contingent display paradigm - which dynamically alters the information visible to participants depending on where the participant is fixating at that given moment in time - was first developed for the study of perceptual span in reading (McConkie \& Rayner, 1975; Rayner, 1975). Observers are free to move their eyes in a temporally and spatially unconstrained manner and a blur or opaque occlusion is applied by software in real-time to:
a) centre a clear window around the point of fixation and blur out peripheral information (called the moving window paradigm); or b) impair vision at and around the fovea to restrict central vision (called the moving mask paradigm). In both conditions the window or mask moves according to the online registration of foveal gaze (Reingold, Loschky, McConkie, \& Stampe, 2003; van Diepen, Wampers, \& d'Ydewalle, 1998). This experimental technique thereby allows a more direct assessment of the information processed by central versus peripheral vision during screen-based tasks, such as the hazard perception element of the driving test ${ }^{1}$.

While this paradigm has yet to be used in simulated driving, it has been used to assess the roles of central and peripheral vision during decision making in sport. Ryu, Abernethy, Mann, and Poolton (2015) asked skilled and novice basketball players to watch a series of basketball video clips and then make a decision on which player was best positioned to receive a pass from the player holding the ball when each clip was occluded at critical time points. Importantly, participants viewed the clips in both moving window (clear central and blurred peripheral vision) and moving mask (clear peripheral and blurred central vision)

\footnotetext{
${ }^{1}$ The hazard perception test is designed to assess the ability of aspirant drivers to identify developing road hazards. It involves watching dashcam video clips / computer generated clips of naturalistic road traffic situations from a driver's perspective, and requires candidates to make a response (e.g., mouse click) to identify hazards that would require the driver to take action (e.g., apply brakes). It is a compulsory part of the driving test in nations such as the United Kingdom and Australia.
} 
1 conditions. Results revealed that the skilled players made better decisions than the novices in

2 both conditions. Importantly, when only peripheral vision was available (moving mask

condition), the performance of novices deteriorated to chance level, while the skilled players

were still able to make accurate decisions. This provides direct evidence that skilled players are better able to use both central and peripheral vision information to support performance, while novices are unable to extract information from the periphery. In the current experiment, we apply the gaze-contingent paradigm to driving for the first time. We expected to reveal similar effects to Ryu et al. (2015). Such results would support the findings of previous driving research suggesting that experienced drivers are more adept at using peripheral vision than novices, but with a more direct measure of peripheral vision than has previously been employed.

\subsection{How to develop effective vision control for safe driving?}

The risk of accidents in driving is thought to be highly associated with drivers' ability to perceive hazards. This ability increases, and accident risk decreases, as drivers become more experienced. Indeed, it has been demonstrated that the failure to effectively detect visual information about potential risks, and the consequent failure to deal with these risks, is the main cause of accidents among newly licensed drivers (Pradhan et al., 2005). Fortunately, the gaze-contingent display paradigm can be used to train visual processing, potentially expediting the development of hazard perception skills in trainee and inexperienced drivers. An example of gaze-contingent perceptual training was provided by Ryu, Mann, Abernethy, and Poolton (2016). They recruited recreational basketball players and asked them to undergo a pre-test, post-test, and retention-test where they viewed basketball video clips and then made a decision on which player was best positioned to receive a pass when the clip was occluded. In between the pre- and post-tests, they underwent either moving window, moving mask, or full vision training, which involved watching the same video clips and making 
1 decisions with either blurred peripheral vision (moving window group), blurred central vision

2 (moving mask group), or unrestricted vision (full vision group). Results revealed that

3 decision making accuracy improved from pre-test to post-test in all three groups. However,

4 those participants whose peripheral vision was blurred displayed further improvements from

5 post-test to a 2-week retention test. Training with impaired peripheral vision thereby

6 enhanced participants' ability to detect and process visual information when transferred back

7 to full vision conditions.

Training with blurred peripheral vision may be expected to yield similar benefits for learner and inexperienced drivers. In a driving scenario, the most crucial cues are likely to be centrally located stimuli (e.g., road or vehicle immediately in front; Mourant \& Rockwell, 1972) or peripherally located moving stimuli (e.g., car changing lanes, cyclist emerging from a side street; Crundall et al., 1999). Blurring peripheral vision may thereby facilitate relevant feature extraction in driving by: a) augmenting the processing of central information via a clear central vision window; b) retaining the processing of relevant peripheral information, since peripheral vision does not rely on high clarity/spatial resolution, and has high sensitivity to moving stimuli (e.g., Vater, Kredel, \& Hossner, 2016, 2017); and c) suppressing the processing of static and likely non-hazardous / irrelevant peripheral information (e.g., advertisement boards, buildings). In doing so, the peripheral blur would help draw the attention of learner drivers towards critical cues that experienced drivers rely on. In this experiment we apply this training approach to examine the effects of gaze-contingent training on hazard perception for the first time.

\subsection{The effects of gaze-contingent vision on the brain}

While our previous research has revealed that experts make superior use of peripheral vision than novices (Ryu et al., 2015) and that blurring peripheral vision during gaze-contingent training can improve decision making performance (Ryu et al., 2016), the mechanisms 
1 underpinning these benefits are unclear. In the Ryu et al. (2016) study, the different training interventions yielded different performance effects, but had no differential impact on the visual search strategies of participants. This led the authors to speculate that the benefits of training with blurred peripheral vision are attributable to a general improvement in information pick-up from both central and peripheral fields rather than increased efficiency of visual search. Specifically, they suggested that the moving window encourages the line-ofgaze and attention to be aligned. In other words, when central vision fixates, we are more likely to pay attention to the content of that fixation when peripheral vision is blurred. While this conclusion seems plausible, it warrants more direct testing via objective neurophysiological measures associated with attention. A candidate measure towards this end is electroencephalographic (EEG) high-alpha power - brain oscillations between $10-12 \mathrm{~Hz}-$ more high-alpha power is associated with neuronal inhibition, while less high-alpha power is associated with neuronal activation (Klimesch, 2012). For example, it is well established that high-alpha power increases (neuronal inhibition) when we close our eyes and remove the opportunity to process visual information, and it promptly decreases (neuronal activation) when we open our eyes and fixate (Adrian \& Matthews, 1934). Based on these assumptions, we hypothesize that if moving window viewing increases attention paid to visual information, neuronal activity should be intensified in the moving window condition. In the current experiments, we combine gaze-contingent eye-tracking and EEG for the first time to examine the effects of gaze-contingent viewing on brain-based measures of attention.

\subsection{The present experiments}

The main objective of our experiments was to examine whether perceptual training, by impairing selective areas of the visual field, can enhance the ability to perceive and detect hazards and thus reduce the risk of accidents. To address this objective, we used the gazecontingent display paradigm to selectively present information to central and peripheral parts 
1 of the visual field. Following the approach of Ryu and colleagues in their gaze-contingent

2 studies of basketball, we first sought to examine the roles of central versus peripheral vision

3 in hazard detection as a function of driving experience (Experiment 1). Then we sought to

4 examine whether gaze-contingent perception training can facilitate driving hazard perception

5 skill (Experiment 2). We expected that participants who train with clear central vision and

6 blurred peripheral vision would improve driving performance to a greater extent than those

7 who did normal training. We also expected that moving window viewing would prompt

8 increased cortical activity.

\section{2. Experiment 1}

In Experiment 1, we examined the roles of central and peripheral vision in hazard perception as a function of driving experience (i.e., experienced versus newly-licensed drivers). We applied the gaze-contingent display paradigm and we measured brain activity to shed light on mechanisms underlying hazard perception during different viewing conditions (i.e., full vision; clear central and blurred peripheral vision; blurred central and clear peripheral vision). We hypothesized that experienced drivers would perform better in the hazard perception test. More importantly, we hypothesized that participants would perform better in the clear central and blurred peripheral vision (i.e., moving window) condition. Finally, we expected that this effect would be accompanied by reduced high-alpha power to indicate greater alignment between line-of-gaze and attention, in the moving window condition than in other viewing conditions.

\subsection{Method}

\subsubsection{Participants}

Twelve experienced $\left(M_{\text {age }}=36.17\right.$ years, $S D=5.81 ; M_{\text {driving experience }}=16.25$ years, $\left.S D=5.64\right)$ and 12 inexperienced drivers $\left(M_{\text {age }}=22.50\right.$ years, $S D=6.97 ; M_{\text {driving experience }}=1.44$ years, $S D$

$25=0.64)$ took part in the experiment. All participants had normal or corrected-to-normal vision 
1 and provided informed consent before commencing the study. Ethical approval was obtained

2 from the institution research ethics committee.

The GPower 3.1 (Faul, Erdfelder, Buchner, \& Lang, 2013) calculation software

indicated that by adopting an alpha of .05 and a sample size of 24 the experiment was

powered at .80 to detect significant between-group, within-group and between-within interaction effects exceeding $f=.27$ (i.e., medium size effects), by mixed-model analysis of variance (Cohen, 1992). Previous studies using the gaze-contingent paradigm for video-based tasks (i.e., Ryu et al., 2015; Ryu et al., 2016) reported large effect sizes ( $\eta_{p}{ }^{2}$ s $\left.>.25\right)$.

Accordingly, if similar effects were to emerge, the samples we recruited in both Experiment 1 and Experiment 2 were adequately powered to detect them.

\subsubsection{Design}

We adopted a 2 (Group: experienced, inexperienced) $\times 3$ (Condition: full vision, moving window, moving mask) mixed-model design. We provide details of the Condition factor in the Test Materials section below.

\subsubsection{Apparatus}

We used an Eyelink 1000 (SR Research Ltd., Mississauga, ON) to record the eye movements of participants and to control the gaze-contingent display. We tracked the monocular corneal reflection from the participants' dominant eye using a sampling rate of $1000 \mathrm{~Hz}$. The system was calibrated by asking participants to fixate on targets in a 9-point reference grid and then validated in the same manner $\left(\right.$ acceptable error to $<0.5^{\circ}$ ). Calibration was repeated if the error at any given point was $>1^{\circ}$. Eye movement data were analysed using Data Viewer software (SR Research Ltd.).

Electroencephalographic activity (EEG) was recorded from thirty-two (32) active electrodes at Fp1, Fp2, AF3, AF4, F7, F3, Fz, F4, F8, FC5, FC1, FC2, FC6, T7, C3, Cz, C4, T8, CP5, CP1, CP2, CP6, P7, P3, Pz, P4, P8, PO3, PO4, O1, Oz, O2 (10-20 system; Jasper, 
1 1958). Additional electrodes were positioned on each mastoid (for offline re-referencing).

2 The signals were sampled at $1024 \mathrm{~Hz}$, with no online filter, using an ActiveTwo amplifier

3 (Biosemi, The Netherlands). Electrode offset was kept below $15 \mathrm{mV}$. TTL triggers were sent

4 to the amplifier from the Eyelink system for the purpose of marking events (e.g., onset and

5 offset of hazards) during the test.

\section{$6 \quad$ 2.1.4. Test materials}

7 Twenty hazard perception video clips (Imagitech Ltd., UK), each around $1 \mathrm{~min}$ in duration,

8 were used in this experiment. All the clips were recorded from a driver's perspective and each clip contained either one or two hazards, defined as any situation that would require the driver to take corrective action (e.g., applying the brake, taking evasive action with the steering wheel) to avoid the hazard (e.g., potential collision), in accord with the criteria applied in the UK driving hazard perception test. Typical hazards included pedestrians, cyclists or other vehicles appearing ahead or from the side of the camera and making a movement towards the driver (e.g., cyclist or vehicle changing lanes and cutting in front of the driver). All our hazards initially appeared at the top or the side of the screen and moved towards the centre as the videos played. We avoided any hazards that exited from the side of the screen as lateral hazards do not represent well in two-dimensional screen-based hazard perception tests (Shahar, Alberti, Clarke, \& Crundall, 2010). Experiment Builder (SR Research Ltd.) software was used to provide the gaze-contingent presentation of the video clips by creating three different viewing conditions: full vision, moving window, and moving mask. In the full vision condition, normal and unmanipulated videos were presented (see Figure 1a). In the moving window viewing condition, a clear circle of 5-degree eccentricity was placed on the point of fixation and visual information outside of this circle was degraded with visual blur (Gaussian blur, 0.5 cycles per degree). The location of the clear window tracked participants' gaze in real time (Figure 1b). Conversely, in the moving mask viewing 
1 condition, the same amount of blur (i.e., 0.5 cycles per degree) was applied to central vision

2 (i.e., 5-degree eccentricity), while information outside central vision was unrestricted (Figure

$31 \mathrm{c})$.

4

5

6

7

8

9
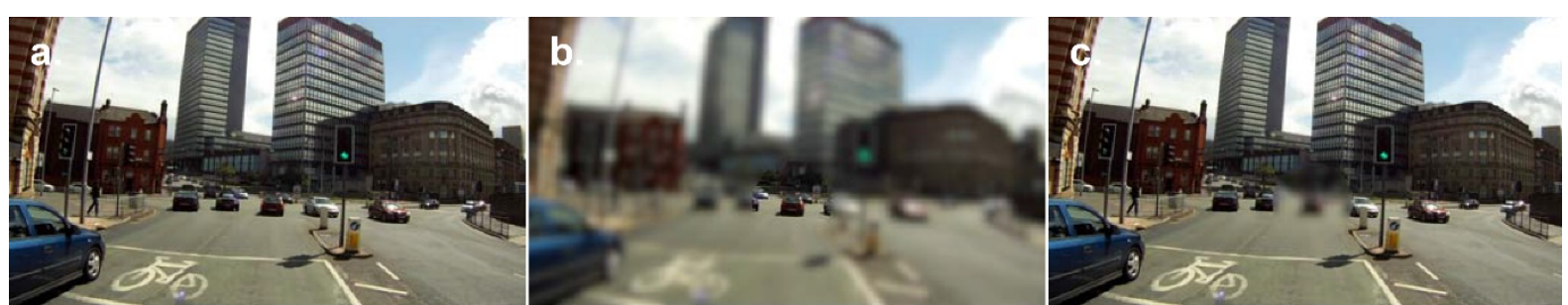

Figure 1. Screenshot of each viewing condition: (a) full vision, (b) moving window, and (c) moving mask conditions. The locations of (b) clear window and (c) blurred mask were changed in real time following participants' gaze (Copyright images Imagitech Ltd., UK).

\subsubsection{Procedure}

Participants were seated $80 \mathrm{~cm}$ from the Eyelink 1000 display monitor (AOC D2769Vh, Taiwan). The horizontal and vertical extents of the monitor subtended $41 \times 24^{\circ}$ of visual angle $($ screen size $=598 \times 336 \mathrm{~mm})$. Following fitting and calibration of the Eyelink system and fitting and signal checking of the EEG system, an experimenter informed the participant of the task. Specifically, we told participants that we would show a series of dashboard camera video clips, and that they were to take perspective of the driver and click the mouse on any hazards that emerged during the clips. We asked participants to respond by clicking the computer mouse on the location of hazards as quickly and as accurately as possible. Each clip contained one or two day-to-day hazards such as pedestrians stepping into the road, cyclists emerging from side roads, other vehicles dangerously cutting across lanes. After this explanation participants were given 6 practice trials to familiarize themselves with the test procedure and the three types of viewing conditions (i.e., full vision, moving window, and moving mask conditions). Participants then completed 60 test trials (the same 20 video clips were shown in each of the three different viewing conditions), separated by a 5-minute interval at the mid-point of the session. The order of trials was randomized. The entire test 
1 session took approximately 2.5 hours including fitting and calibration of EEG and eye-

2 tracking systems.

\section{2.1.6. Dependent variables and data analyses}

\section{2.1.6.1. Performance data}

5 Within each video clip, hazard events were time-stamped in the Experiment builder software.

6 In line with UK hazard perception driving test hazard classification criteria, the clips

7 contained stimuli that were initially nonthreatening, but then developed into a hazard requiring the driver to act. For example, a pedestrian on the sidewalk would initially be nonthreatening, but may develop into a hazard if they stepped towards the roadway. The opening of the designated "hazard windows" within our clips was the first frame at which a stimulus became a hazard that would require driver action (i.e., the point at which the pedestrian stepped towards the roadway in the above example). The closing of the hazard window was the point at which there would be insufficient time to react appropriately to that hazard in a real driving situation. This time-stamp information was provided by Imagitech Ltd. following assessment of the clips by their expert raters using UK hazard perception driving test hazard classification criteria. The spatial location of each hazard was identified on a frame-by-frame basis in each clip and a "hazard area" was established by creating an invisible area around the hazard at $150 \%$ of the hazard size using Experiment Builder software. We created a hazard area slightly larger than the actual hazard in each frame to account for the dynamic nature of video; when the hazards were small and fast moving it was difficult to click precisely within the hazard location. Our enlarged hazard area allowed mouse clicks that were a few pixels behind or ahead of a moving hazard to be marked as correct, thereby minimizing any ambiguity zones around the hazard perimeter. This approach provides a balance to protect against false positive responses (e.g., participant clicking at the right time without recognising the hazard), such as can occur in paradigms that do not 
1 consider the location of clicks. It also helps minimize false negative responses (e.g.,

2 participant correctly identifies the hazard, but clicks a few pixels ahead of the moving hazard

3 due to perceptual error), as might have occurred if we did not enlarge the hazard zone. The

4 average duration of a hazard event was $3.6 \mathrm{sec}$, and each 1 min clip contained one or two

5 hazards. Accordingly, hazard events were only a small part of each clip. To register a correct

6 response participants had to click on the correct spatial location of the hazard (i.e., click

7 somewhere within the invisible $150 \%$ scaled hazard area) within the designated hazard time

8 window (mean $=3.6 \mathrm{~s}$ for our clips) that a driver would have to take corrective action and avoid a collision in a real driving scenario. Pilot testing revealed that most participants registered many "false positive" clicks during each video clip (e.g., they may have correctly clicked the hazard, but also clicked 4-5 other non-hazards during each 1-min video). Therefore, a crude measure of whether participants correctly identified hazards or not was not particularly informative (participants adopting a strategy of clicking more frequently were positively advantaged on this metric as they were more likely to hit the target by chance). Instead we extracted two more fine-grained measures of hazard perception performance:

Hazard discrimination. We calculated the percentage of correct clicks, by dividing the number of correct clicks on hazards by the sum of all clicks (i.e., hazardous and nonhazardous segments) in each video clip. This is a metric of hazard discrimination, as it indexes ability to discriminate between hazardous and non-hazardous situations, where a higher score indicates better performance. For example in a clip with one hazard, a participant who clicks only on the genuine hazard would score $100 \%$ on this measure while a participant who correctly identified the genuine hazard, but also clicked on three other nonhazardous segments of the clip would score $25 \%$. Higher scores indicate better performance. hazard detection time for all hazards that were correctly identified. Hazard detection time was 
1 the mean time (in milliseconds) that elapsed from the time of the participant's first mouse

2 click response to the hazard, to the end time of the same hazard. All values are negative, with

3 greater negative values indicating earlier detection of the hazard and, thus, better hazard

4 perception performance.

\section{$5 \quad$ 2.1.6.2. Gaze behaviour data}

6 Three dependent variables were computed for analysis. First, to determine whether the

7 duration of the visual fixations changed as a result of the manipulation of visual information,

8 the mean fixation duration (in $\mathrm{ms}$ ) was calculated by averaging the duration of all fixations in

9 each video clip. Second, as a proxy assessment for whether the breadth of the search changed as a result of viewing condition, mean saccadic amplitude (in degrees of visual angle) was calculated as the average angular subtense of all saccades in each trial to measure the breadth of the search. Third, time difference between hazard start time and fixation onset time on hazard was calculated to determine differences in fixation onset time on hazard in each trial.

We expected a narrower search strategy to be induced by the moving window condition, with longer fixation durations and smaller saccadic amplitudes.

\subsubsection{EEG data}

To determine cortical activity, high-alpha power $(10-12 \mathrm{~Hz})$ during each trial was calculated for $\mathrm{Fz}, \mathrm{Cz}, \mathrm{Pz}$, and $\mathrm{Oz}$ sites. Firstly, offline signal processing was performed using EEGLAB (Delorme \& Makeig, 2004), ERPLAB (Lopez-Calderon \& Luck, 2014), and bespoke scripts in Matlab (Mathworks Inc., USA). Data were down-sampled to $250 \mathrm{~Hz}$, re-referenced to the average mastoids (no bad channels were identified), and filtered 1 to $30 \mathrm{~Hz}$ (Butterworth, $12 \mathrm{~dB} / 40$ roll-off order 2 non-causal). Data were segmented around each video clip (i.e., a trial) into 66 seconds epochs in order to have 3 seconds of buffer before and after the end of the trial. Independent component analysis (ICA) was performed via the RunICA informax algorithm (Makeig, Bell, Jung, \& Sejnowski, 1966) on these same EEG data (32 channels, 
1 yielding the same number of independent components). Artefactual components (e.g., eye or muscle related) flagged by automated procedures (SASICA plugin; Chaumon, Bishop, \& Busch, 2015) were then visually inspected and manually rejected.

Following artefact removal, a wavelet convolution was applied to obtain estimates of alpha power during each trial period. The application of wavelet is advantageous because it improves the stationarity of the signal and obtains a reliable spectral estimation. This technique was implemented by convolving the Fast-Fourier Transform (FFT) power spectrum of each EEG artefact-free epoch with a family of complex Morlet wavelets, defined as a Gaussian-windowed complex sine wave: $e^{i 2 \pi t f} e^{-t^{2} / 2 \sigma^{2}}$; where $t$ is time, $f$ is frequency bin, which increased from 4 to $30 \mathrm{~Hz}$ in 30 logarithmic steps, and $\sigma$ defines the width of each

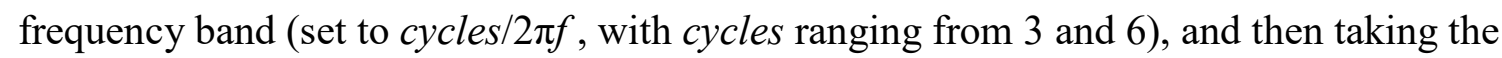
inverse FFT to obtain the analytic signal $z$. Estimates of instantaneous power were then obtained from the complex signal of each frequency bin $(f)$ as the squared magnitude of the analytic signal defined as $Z_{t}$ (power time series: $\left.p_{t}=\operatorname{real}\left(z_{t}\right)^{2}+\operatorname{imag}\left(z_{t}\right)^{2}\right)$. Each trial was then baseline normalized by means of a decibel change transformation $(\mathrm{dB}$ change $=$ $10 \cdot \log 10$ trial/reference) with reference period being -1000 to -500 milliseconds prior to the beginning of the trial (participants fixated the blank computer screen during this time). To obtain average activity during the trial, we averaged decibel corrected high-alpha power (i.e., 10-12 Hz frequency bins) across the whole of each trial within each participant and condition.

\subsubsection{Statistical analyses}

The dependent variables were analysed using 2 (Group: Experienced, Inexperienced) $\times 3$ (Viewing condition: Full vision, Moving window, Moving mask) analyses of variance 
1 (ANOVAs) with repeated measures on the second factor ${ }^{2}$. Significant main and interaction

2 effects were followed up with least significant difference (LSD) post-hoc tests. For all

3 inferential tests, effect sizes were reported as partial eta-squared values and a Greenhouse-

4 Geisser correction was applied to the degrees of freedom when the assumption of sphericity

5 was violated. The alpha level for all comparisons was set at $p=.05$.

\section{2.2. Results}

7 ANOVAs revealed a main effect for group for hazard discrimination and main effects for condition for all other variables with the exception of EEG activity at parietal $(\mathrm{Pz})$ and occipital $(\mathrm{Oz})$ sites. There were no group $\times$ condition interactions. The statistical outcomes are summarised in Table 1, and the means and outcomes of post-hoc analyses are illustrated in Figures 2-4. In brief, the group main effect confirmed that experienced drivers displayed better hazard discrimination than inexperienced drivers (Figure 2a). The condition main effects showed that hazard discrimination and hazard detection time were similar in the full vision and moving window conditions but were impaired in the moving mask condition (Figure 2). Gaze behaviour showed that fixation durations were longest, and saccadic amplitudes were smallest in the moving window condition, while the full vision condition produced the fastest hazard fixation onsets (Figure 3). Finally, EEG analyses revealed that frontal $(\mathrm{Fz})$ and central $(\mathrm{Cz})$ EEG high-alpha power was reduced, signifying greater cortical activation, in the moving window condition (Figure 4).

\footnotetext{
${ }^{2}$ Additionally, for the performance measures only, we conducted 2 (Group: Experienced, Inexperienced) $\times 3$ (Clip exposure: $1^{\text {st }}, 2^{\text {nd }}$, and $3^{\text {rd }}$ presentation) ANOVAs to check whether there was a familiarity effect due to repeated exposure to the video clips. ANOVAs revealed no main effect for clip exposure, $F$ 's $(2,44)=0.25$ $2.23, p$ 's $>.05, \eta_{p}{ }^{2} \mathrm{~s}=.01-.09$, and no group $\times$ clip exposure interactions, $F$ 's $(2,44)=0.09-0.29, p$ 's $>.05$, $\eta_{p}{ }^{2} \mathrm{~s}=.00-.13$. These control analyses rule out the possibility that participants memorised the hazards across the repeated trials.
} 
1 Table 1. The results of ANOVAs for performance data, gaze behaviour, and cortical activity

2 in Experiment 1.

\begin{tabular}{|c|c|c|c|c|c|}
\hline & Dependent variables & Effect & $d f$ & $F$ & $\eta_{p}^{2}$ \\
\hline \multirow{6}{*}{$\begin{array}{c}\text { Performance } \\
\text { data }\end{array}$} & \multirow{3}{*}{ Hazard discrimination } & Group & 1,22 & $5.53 *$ & .20 \\
\hline & & Condition & $1.48,32.62$ & $5.67 *$ & .46 \\
\hline & & Group $\times$ Condition & $1.48,32.62$ & 2.47 & .10 \\
\hline & \multirow{3}{*}{ Hazard detection time } & Group & 1,22 & 1.90 & .05 \\
\hline & & Condition & 2,44 & $18.58 * *$ & .46 \\
\hline & & Group $\times$ Condition & 2,44 & .19 & $<.01$ \\
\hline \multirow{9}{*}{$\begin{array}{c}\text { Gaze } \\
\text { behaviour }\end{array}$} & \multirow{3}{*}{ Mean fixation duration } & Group & 1,22 & .01 & $<.01$ \\
\hline & & Condition & 2,44 & $5.90 *$ & .21 \\
\hline & & Group $\times$ Condition & 2,44 & 1.47 & .06 \\
\hline & \multirow{3}{*}{$\begin{array}{l}\text { Mean saccadic } \\
\text { amplitude }\end{array}$} & Group & 1,22 & .94 & .04 \\
\hline & & Condition & $1.59,35.06$ & $123.22 * *$ & .85 \\
\hline & & Group $\times$ Condition & $1.59,35.06$ & .87 & .04 \\
\hline & \multirow{3}{*}{$\begin{array}{c}\text { Difference between } \\
\text { hazard start and fixation } \\
\text { onset time on hazards }\end{array}$} & Group & 1,22 & .31 & .01 \\
\hline & & Condition & 2,44 & $8.92 * *$ & .29 \\
\hline & & Group $\times$ Condition & 2,44 & .15 & .01 \\
\hline \multirow{12}{*}{$\begin{array}{l}\text { Cortical } \\
\text { activity }\end{array}$} & \multirow{3}{*}{$\mathrm{Fz}$} & Group & 1,22 & 1.00 & .04 \\
\hline & & Condition & 2,44 & $3.68 *$ & .14 \\
\hline & & Group $\times$ Condition & 2,44 & 1.08 & .05 \\
\hline & \multirow{3}{*}{$\mathrm{Cz}$} & Group & 1,22 & .21 & .01 \\
\hline & & Condition & 2,44 & $3.63 *$ & .14 \\
\hline & & Group $\times$ Condition & 2,44 & 1.42 & .06 \\
\hline & \multirow{3}{*}{$\mathrm{Pz}$} & Group & 1,22 & $<.01$ & $<.01$ \\
\hline & & Condition & 2,44 & .45 & .02 \\
\hline & & Group $\times$ Condition & 2,44 & 1.05 & .05 \\
\hline & \multirow{3}{*}{$\mathrm{Oz}$} & Group & 1,22 & .01 & $<.01$ \\
\hline & & Condition & 2,44 & 2.56 & .10 \\
\hline & & Group $\times$ Condition & 2,44 & 1.13 & .05 \\
\hline
\end{tabular}


a.

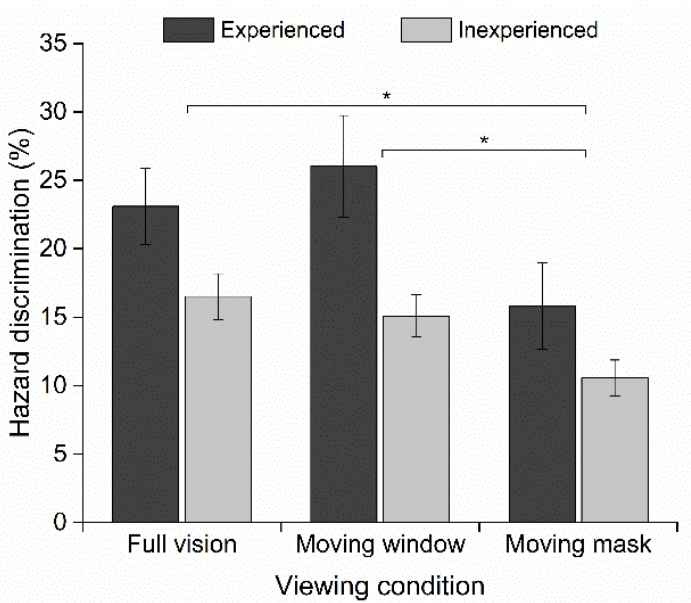

b.

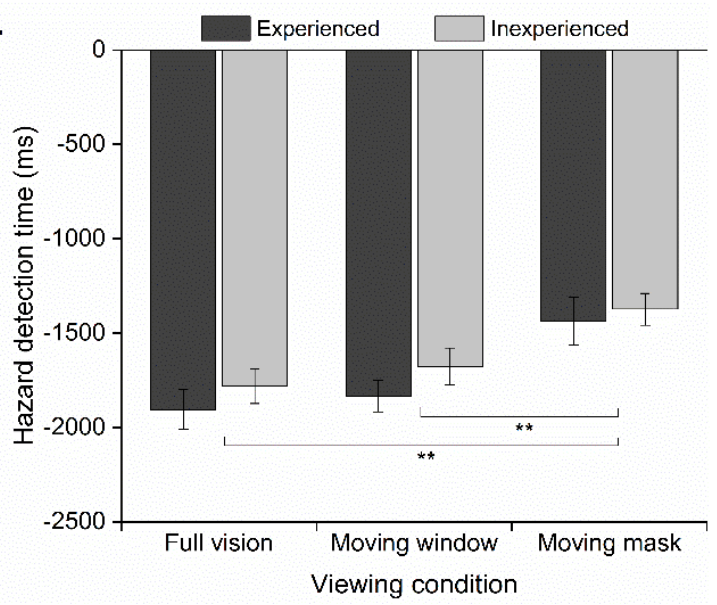

Figure 2. Mean (a) hazard discrimination and (b) hazard detection time for experienced and inexperienced drivers in Experiment $1(* p<.05, * * p<.01)$. In hazard detection time (b), " 0 " indicates end of hazard window, so more negative values indicate better performance. Error bars indicate the standard error of the mean.

a.

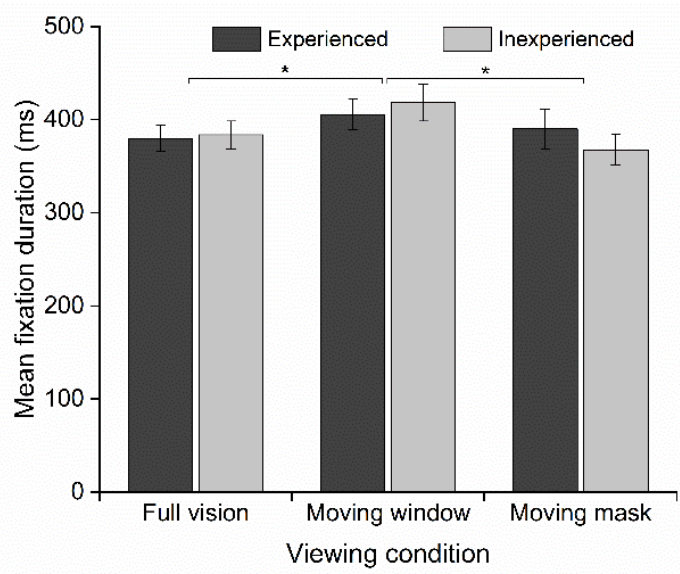

b.

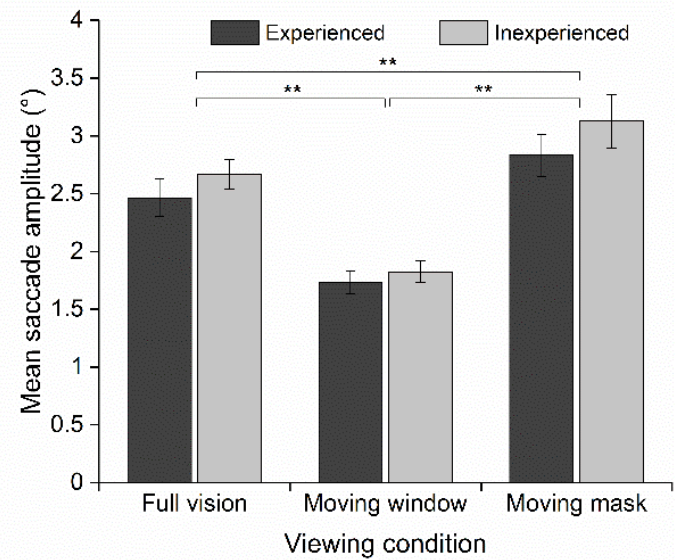

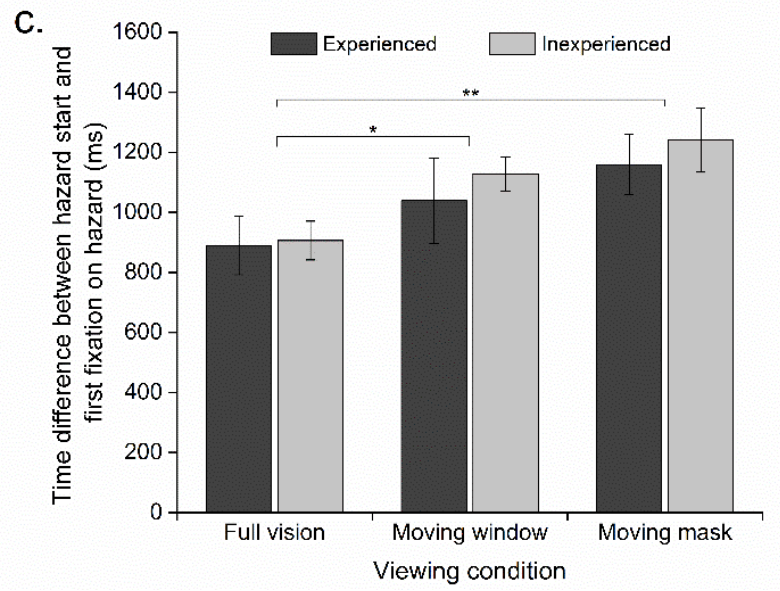

8 Figure 3. Mean (a) fixation duration, (b) saccadic amplitude, and (c) time difference 9 between hazard start and first fixation on hazards for experienced and inexperienced drivers in Experiment $1\left(* p<.05,{ }^{* *} p<.01\right)$. Error bars indicate the standard error of the mean. 
a. Fz

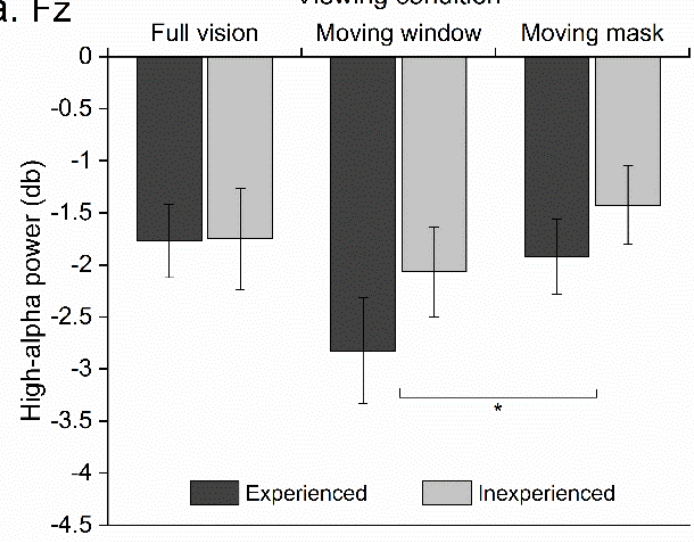

c. $\mathrm{Pz}$

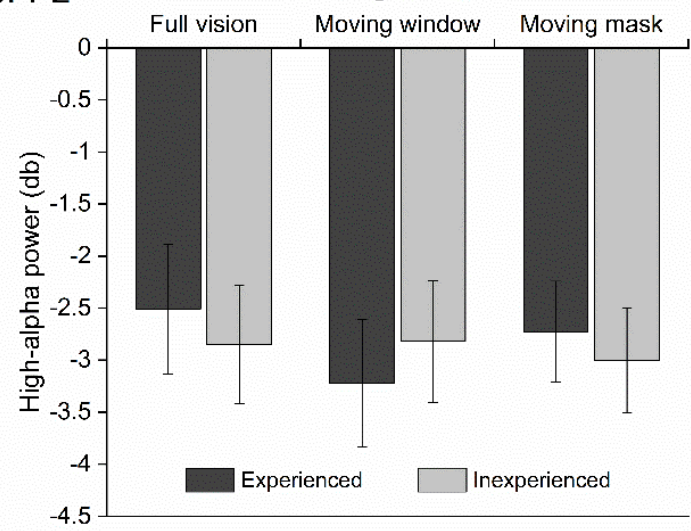

b. $\mathrm{Cz}$

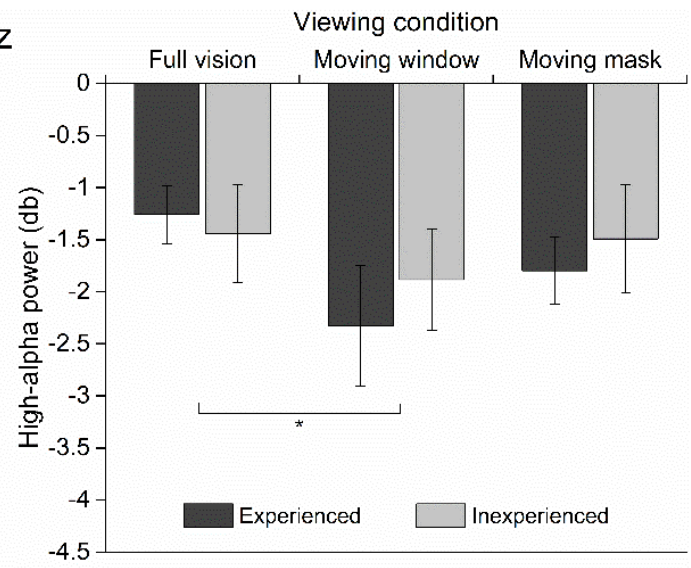

d. $\mathrm{Oz}$

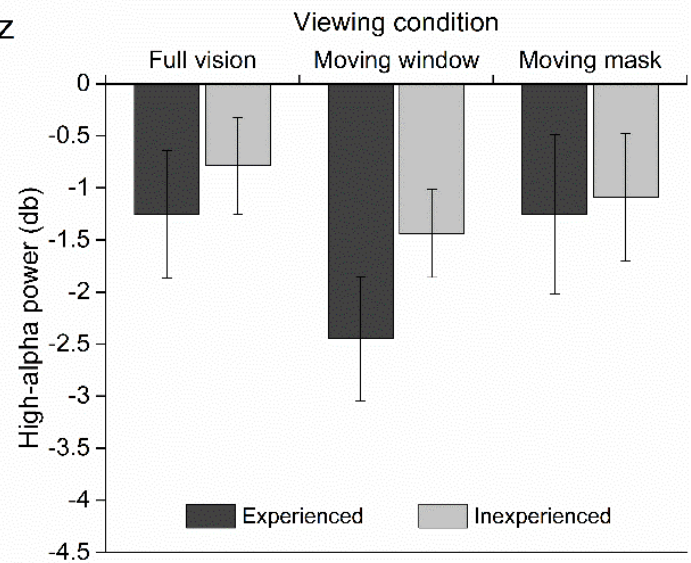

Figure 4. High-alpha power in the four regions in Experiment 1: (a) frontal (Fz), (b) central $(\mathrm{Cz})$, (c) parietal $(\mathrm{Pz})$, and $(\mathrm{d})$ occipital $(\mathrm{Oz})(* p<.05)$. Error bars indicate the standard error of the mean.

\subsection{Discussion}

In Experiment 1, we employed eye-tracking and brain imaging measures to provide a

comprehensive examination of the roles of central and peripheral vision in the hazard

perception ability of experienced and inexperienced drivers. Three different viewing conditions (i.e., full vision, moving window, and moving mask conditions) were used to directly assess the information pick-up from central and peripheral vision while watching hazard perception video clips. We first hypothesized that experienced drivers would outperform inexperienced drivers on the hazard perception test. Results revealed that experienced drivers were better than inexperienced drivers at discriminating hazardous and non-hazardous situations. This provides some support for our hypothesis and previous studies 
1 (e.g., Horswill \& McKenna, 2004; Underwood et al., 2008). However, there were no

2 significant group differences in hazard detection time.

The second hypothesis was that the moving window condition would support the best performances. There was limited support for this hypothesis. While the moving window condition did indeed foster superior hazard discrimination as well as faster hazard detection when compared to the moving mask condition, it was not different to the full vision condition, suggesting that full vision and moving window viewing conditions were equivalent. There was some evidence that the moving window condition was better than the full vision condition in terms of hazard processing time. Specifically, while the moving window and the full vision conditions yielded similar hazard detection times (Figure 2b), participants took longer to fixate on hazards in the moving window condition (Figure 3c). This delay in looking at hazards combined with no delay in responding to hazards provides evidence that the moving window condition encouraged purposeful fixations that allowed faster information processing compared to the full vision condition. This was also supported by the increased fixation durations and smaller saccade amplitudes in the moving window condition, which reflects a narrowed and concentrated search strategy. Taken together, the findings indicate that central vision is important during hazard perception, and the removal of central vision (i.e., moving mask condition) significantly degrades hazard perception for both experienced and inexperienced drivers.

Our final hypothesis was that EEG high-alpha power would be reduced to indicate greater attention devoted to information processing in the moving window compared to the other viewing conditions. This hypothesis was partially supported as high-alpha power was reduced at frontal and central electrodes during the moving window condition. Since less high-alpha power reflects relatively greater neuronal activation, and since frontal and central electrodes overlie brain areas associated with perceptual-motor decision making and motor 
1 response programming (e.g., Ashe, Lungu, Basford, \& Lu, 2006; Cooke et al., 2015), our

2 finding provides more evidence that the moving window condition encourages line-of-gaze

3 and attention to be aligned, and this could be of benefit to performance.

\section{3. Experiment 2}

5 Experiment 1 provides new neurophysiological evidence to support the idea that the moving

6 window viewing condition helps ensure line-of-gaze and attention are aligned. It also

7 provides encouraging evidence that the moving window paradigm could be employed as a

8 training tool that should be at least as effective (and potentially more effective) than full

$9 \quad$ vision training in helping new drivers to pay attention and to better identify road hazards.

10 Experiment 2 will provide a direct test of this suggestion. We sought to examine whether

11 perceptual training can enhance hazard perception ability among unlicensed trainee drivers.

Participants were assigned to one of two training groups: a moving window training group

(training with clear central vision and blurred peripheral vision) and a full vision training group (training with unrestricted vision). We are particularly interested in maximizing the learning trajectory of learner drivers, so we sought to explore the possible differences between the two optimal conditions from Experiment 1 (i.e., the full vision and moving window conditions) rather than the moving mask condition, which was consistently and significantly less effective (for detecting hazards). We hypothesized that the moving window group who trained with blurred peripheral vision would improve their hazard perception more than normal/unmanipulated vision training group. This is because moving window viewing encourages gaze and attention to move into alignment, thereby increasing the processing of the most relevant cues in both central and peripheral vision.

\subsection{Method}

\subsubsection{Participants}


1 Twenty unlicensed drivers, who had either begun driving lessons or had indicated an

2 intention to begin driving lessons within the next month, participated in Experiment 2.

3 Participants were assigned to either a full vision training group $\left(M_{\mathrm{age}}=22.60\right.$ years, $S D=$

$41.90)$ or a moving window training group $\left(M_{\mathrm{age}}=21.80\right.$ years, $\left.S D=3.99\right)$. All participants

5 had normal or corrected-to-normal vision and provided informed consent before commencing

6 the study. Ethical approval was obtained from the institution research ethics committee.

\section{3.1.2. Design}

8 We adopted a 2 (Group: full vision training, moving window training; between-participant

9 factor $\times 3$ (Test: pre-test, post-test, retention test; within-participant factor) mixed-model design. In the pre-test, post-test, and retention test phases, participants watched 20 video clips in full-vision and 20 video clips in moving window conditions, as per Experiment 1. Importantly, the pre-test and the post-test were separated by the training intervention (90 full vision video clips different from the 20 testing video clips for members of the full vision group; 90 moving window video clips different from the 20 testing video clips for members of the moving window group), spread evenly over 3 days. The retention test was 1-month after the post-test and allowed examination of the extent to which any benefits of the training intervention had been retained. More details about the test and training phases are provided in the Procedures section below.

\subsubsection{Apparatus}

In Experiment 2, we used 16 active electrodes positioned on the scalp at Fp1, Fp2, F3, Fz, F4, T7, C3, Cz, C4, T8, P3, Pz, P4, O1, Oz, O2 to record cortical activity (10-20 system; Jasper, 1958). All other setup and apparatus used in Experiment 2 were identical to Experiment 1.

\subsubsection{Test and training materials} were shown in each of two different viewing conditions: full vision (unrestricted normal 
1 vision) and moving window (clear central and blurred peripheral vision) viewing conditions.

2 Each clip contained between 1 and 4 hazards $(M=2.2)$ with an average duration of $5.7 \mathrm{sec}$

3 per hazard ${ }^{3}$. We deliberately used clips with more hazards and longer duration hazards in

4 Experiment 2 given the longitudinal design (i.e., to reduce the risk of performance ceiling

5 effects) and based on the inexperienced nature of the sample.

6

In the training phase of the experiment, participants watched video clips that we created especially for this experiment, recorded using a high-definition dashcam attached to a windscreen (Thinkware Dashcam F770, Thinkware, Korea). The angle and structure were identical to that seen in the video clips used in the test phase, and we ensured that our bespoke training clips matched the clips used in the test phase for duration, type and number of hazards. Two experienced drivers assigned and agreed the hazards in our test clips, using the same criteria as applied in the test phase (i.e., hazard is a situation that would require the driver to take corrective action to avoid a collision). From approximately 50 hours of dashcam footage, we selected 90 1-min video clips for use in the training sessions.

\subsubsection{Procedures}

Experiment 2 consisted of four parts: pre-test, training intervention, post-test, and retention test (Figure 5). The pre-test took place 1 day prior to the commencement of the training intervention. The training intervention occurred over 3 days and the post-test took place one day after training intervention. Finally, the retention test was scheduled 1 month after the post-test.

\subsubsection{Pre, Post, and Retention tests}

The procedure of this test phase of the experiment was identical to the Experiment 1 except participants watched only two different viewing conditions in Experiment 2: full vision and

\footnotetext{
${ }^{3}$ The same test-phase clips were used for all conditions and across all groups within each experiment, so any between group / between condition differences should not be differentially influenced by hazard duration.
} 
1 moving window viewing. We omitted the moving mask condition from Experiment 2

2 because it was clear that this condition impaired performance. At the start of the session

3 participants were given 6 practice trials to familiarize themselves with the test procedure and

4 the two types of viewing conditions (i.e., full vision and moving window viewing

5 conditions). Participants then completed 40 test trials (20 video clips presented in full vision

6 and the same 20 clips presented in moving window viewing), with a mandatory 5 -min

7 interval at the mid-point of the session. All trials were randomized. The entire test session

8 took approximately 2 hours including fitting and calibration of EEG and eye-tracking

9 systems.

10

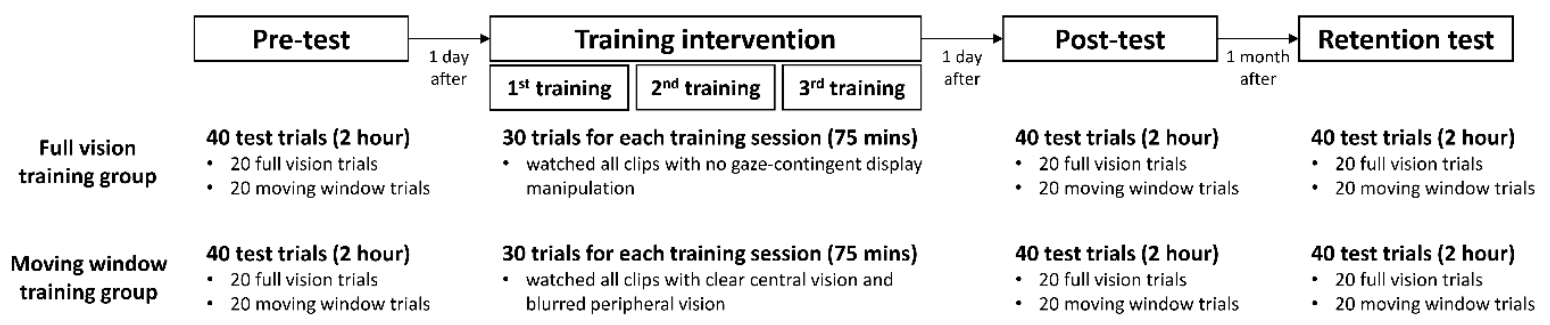

Figure 5. A schematic of the Experiment 2 timeline for full vision and moving window training groups.

\subsubsection{Training intervention}

In the training phase of the experiment, 30 hazard perception video clips were viewed in a random order in each of the three training sessions (a total of 90 trials). The 90 video clips (90 trials) used in the training intervention were different from the 20 video clips (40 trials) used for testing. Importantly, after each trial, feedback on performance was provided by showing each frame containing hazardous situations with correct hazard(s) highlighted alongside a brief description of the nature of the hazard. The twenty participants were randomly assigned to one of two training groups: (i) a full vision training group $(n=10)$ who watched all their training phase clips with no gaze-contingent display manipulation; and (ii) a 
1 moving window training group $(n=10)$ who watched all their training phase clips with clear

2 central vision and blurred peripheral vision. EEG data were not recorded during the training

3 phase. Each training session, including calibration and feedback, took approximately 75 mins

4 to complete. Training sessions were scheduled on separate days, and were separated by 1-2

5 days $(M$ intersession interval $=1.38$ days $)$.

\section{$6 \quad$ 3.1.6. Dependent variables and data analyses}

\section{3.1.6.1. Performance data}

8 We focused our analyses on performance in the test phase of the experiment. In accordance

9 with Experiment 1, we calculated two metrics of performance.

10 Hazard discrimination. To further increase the sensitivity of this metric, we refined the

11 measure of hazard discrimination from Experiment 1 to Experiment 2 by segmenting the hazard window and offering more points for early than for late hazard responses. This approach also matched more closely the scoring system employed in the UK driving hazard perception test. Specifically, we adopted a points system where the duration of each hazard window was divided into five equal segments, and a mouse click in the first segment (i.e., an early response) was awarded five points, while a click in the final segment (i.e., a late response) was awarded one point. To ensure we tested hazard discrimination (i.e., ability to distinguish between hazards and non-hazards) and to mitigate against the risk of participants repeatedly clicking the mouse to "cheat" the system, we divided their total number of points for each clip by the total number of mouse clicks for that clip. Scores range from 0 (hazard 
1 not detected) to 5 (hazards detected at earliest segment and no false positive clicks). Higher

2 scores indicate better performance ${ }^{4}$.

3 Hazard detection time. This measure was calculated in the same way as described in

4 Experiment 1.

\section{$5 \quad 3.1 .6 .2$. Gaze behaviour data}

6 The analyses of gaze data were identical to Experiment 1.

\section{3.1.6.3. EEG data}

8 EEG data were analysed at $\mathrm{Fz}, \mathrm{Cz}, \mathrm{Pz}$, and $\mathrm{Oz}$ in the same way as in Experiment 1.

9

\subsubsection{Statistical analyses}

In accordance with our aim to determine whether the training intervention would enhance hazard perception among unlicensed trainee drivers during naturalistic conditions, our analyses focus on performance, gaze, and EEG when viewing full vision condition trials in the test phase ${ }^{5}$. We performed 2 (Group: Full vision training, Moving window training) $\times 3$ (Test occasion: Pre, Post, Retention) analyses of variance (ANOVAs) with repeated measures on the second factor. Significant main and interaction effects were followed up with least significant difference (LSD) post-hoc tests. For all inferential tests, effect sizes were reported as partial eta-squared values and a Greenhouse-Geisser correction was applied to the degrees of freedom when the assumption of sphericity was violated. The alpha level for all comparisons was set at $p=.05$.

\subsection{Results}

\footnotetext{
${ }^{4}$ While the hazard discrimination metric employed in Experiment 1 accounted for the problem of false positive clicks, it could not distinguish between two participants who made the same number of false positive clicks, but who varied in the latency of their correct clicks, as all correct clicks were weighted the same. The approach adopted in Experiment 2 solves this problem by awarding greater credit for correct responses that occur earlier in the hazard window. As location and segmentation of hazard windows were pre-programmed and analysed online, we were unable retrospectively to apply this refined strategy to the data collected in Experiment 1. ${ }^{5}$ The results of analyses performed on our performance, gaze, and EEG measures in the moving window condition are reported in the supplementary material. The effects are largely consistent with those from the full vision condition.
} 


\section{$1 \quad$ 3.2.1. Performance data}

2 Hazard discrimination. Hazard discrimination results are illustrated in Figure 6a. ANOVA

3 revealed a significant main effect for group, $F(1,18)=4.49, p<.05, \eta_{p}{ }^{2}=.20$, and test

4 occasion, $F(1.33,23.93)=20.28, p<.001, \eta_{p}{ }^{2}=.53$. The moving window training group

5 showed better hazard discrimination than the full vision training group. Hazard

6 discrimination scores improved from pre-test to post-test $(p<.05)$, and from post-test to

7 retention test $(p<.05)$. Although the interaction between group and test occasion failed to

8 reach statistical significance, $F(1.33,23.93)=2.66, p=.11, \eta_{p}{ }^{2}=.13$, we proceeded with

9 pre-planned comparisons on the basis of our a priori hypothesis that the moving window training would be more effective than full vision training. These tests revealed that the moving window training group increased their hazard discrimination scores from pre-test $(M$ $=1.22, S D=0.10)$ to post-test $(M=1.59, S D=0.06 ; p<.05)$, and then again from post-test to retention test $(M=1.80, S D=0.09 ; p<.05)$. Hazard discrimination scores of the full vision training group did not change across pre-test $(M=1.12, S D=0.10)$, post-test $(M=$ $1.38, S D=0.09)$, or retention test $(M=1.39, S D=0.10 ; p$ 's $>.05)$.

Hazard detection time. Hazard detection time data are illustrated in Figure 6b. ANOVA

17 failed to reveal any significant main effects for test occasion, $F(2,36)=3.11, p>.05, \eta_{p}{ }^{2}$ $18=.15$, for group, $F(1,18)=1.14, p>.05, \eta_{p}{ }^{2}=.06$, and there were no significant training 19 group $\times$ test occasion interaction, $F(2,36)=1.08, p>.05, \eta_{p}^{2}=.06$. 
a.

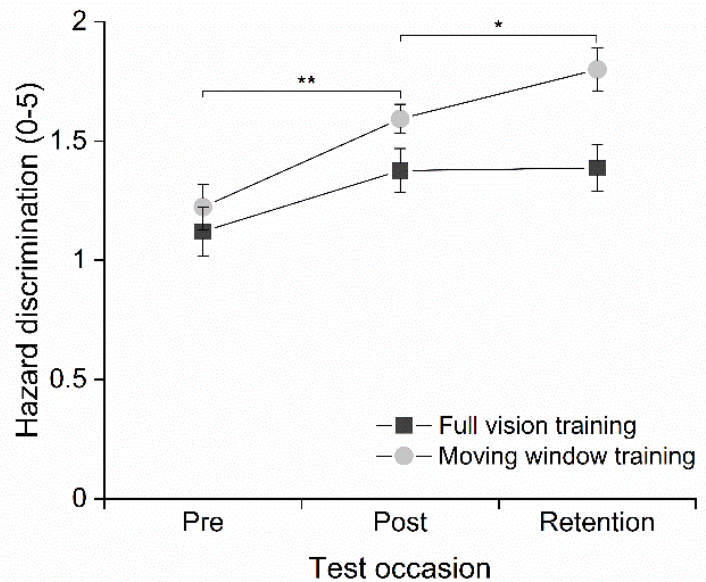

b.

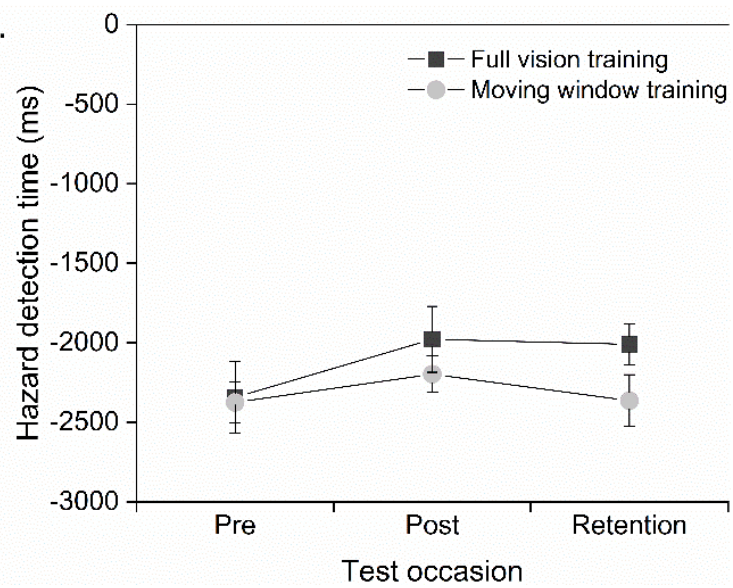

2 Figure 6. Mean (a) hazard discrimination and (b) hazard detection time for the full vision 3 training group and moving window training group in Experiment $2\left(* p<.05\right.$, $\left.{ }^{* *} p<.01\right)$. In 4 hazard detection time (b), "0" indicates end of hazard window, so more negative values 5 indicate better performance. Error bars indicate the standard error of the mean.

7 3.2.2. Gaze behaviour

8 The gaze behaviour data are summarized in Table 2. ANOVAs revealed no significant

9 differences between the two training groups, $F$ 's $(1,18)=0.11-1.10, p$ 's $=.31-.75, \eta_{p}{ }^{2}$ s

$10=.01-.06$, no main effects for test occasion, $F^{\prime} \mathrm{s}(2,36)=1.10-2.57, p^{\prime} \mathrm{s}=.09-.35, \eta_{p}{ }^{2}{ }^{\prime} \mathrm{s}$

$11=.06-.13$, and no interaction effects between training group and test occasion, $F^{\prime}$ 's $(2,36)=$

$120.22-1.13, p$ 's $=.32-.80, \eta_{p}{ }^{2}{ }^{\prime} \mathrm{s}=.01-.05$, for any of the gaze measures. In sum, the

13 training interventions had no impact on gaze behaviour. 
Table 2. Mean $(S D)$ fixation duration, mean saccade amplitude, and time difference between hazard start and first fixation onset time on hazards for full vision training group and moving window training group in Experiment 2.

\begin{tabular}{|c|c|c|c|c|c|c|c|c|c|}
\hline \multirow{2}{*}{$\begin{array}{l}\text { Training } \\
\text { group }\end{array}$} & \multicolumn{3}{|c|}{ Mean fixation duration } & \multicolumn{3}{|c|}{ Mean saccade amplitude } & \multicolumn{3}{|c|}{$\begin{array}{l}\text { Time difference between hazard start } \\
\text { and first fixation onset time on hazards }\end{array}$} \\
\hline & Pre & Post & Retention & Pre & Post & Retention & Pre & Post & Retention \\
\hline $\begin{array}{c}\text { Full } \\
\text { vision } \\
\text { training }\end{array}$ & $\begin{array}{l}383.29 \\
(45.99)\end{array}$ & $\begin{array}{c}414.02 \\
(104.00)\end{array}$ & $\begin{array}{l}419.36 \\
(76.82)\end{array}$ & $\begin{array}{l}2.61 \\
(0.26)\end{array}$ & $\begin{array}{l}2.81 \\
(0.16)\end{array}$ & $\begin{array}{c}2.83 \\
(0.41)\end{array}$ & $\begin{array}{l}1016.36 \\
(456.56)\end{array}$ & $\begin{array}{l}1005.41 \\
(395.17)\end{array}$ & $\begin{array}{c}998.50 \\
(366.33)\end{array}$ \\
\hline $\begin{array}{l}\text { Moving } \\
\text { window } \\
\text { training }\end{array}$ & $\begin{array}{l}412.75 \\
(76.65)\end{array}$ & $\begin{array}{c}395.17 \\
(105.71)\end{array}$ & $\begin{array}{c}442.01 \\
(105.63)\end{array}$ & $\begin{array}{c}2.46 \\
(0.49)\end{array}$ & $\begin{array}{c}2.62 \\
(0.70)\end{array}$ & $\begin{array}{c}2.56 \\
(0.66)\end{array}$ & $\begin{array}{l}1370.49 \\
(606.89)\end{array}$ & $\begin{array}{l}1179.84 \\
(597.35)\end{array}$ & $\begin{array}{c}978.99 \\
(700.65)\end{array}$ \\
\hline
\end{tabular}




\section{$1 \quad 3.2 .3$. Cortical activity}

2 The EEG high-alpha power data are illustrated in Figure 7. ANOVAs revealed no main

3 effects of test occasion at any of the sites, $F^{\prime} \mathrm{s}(2,36)=0.04-1.51, p^{\prime} \mathrm{s}=.13-.96, \eta_{p}{ }^{2}{ }^{\prime} \mathrm{s}$

$4=.002-.08$. However, there was a significant main effect for group at $\mathrm{Fz}, F(1,18)=5.83, p$

$5<.05, \eta_{p}{ }^{2}=.25$, members of the moving window training group displayed less high-alpha

6 power than members of the full vision training group at all timepoints. Importantly, there was

7 also a significant group $\times$ test occasion interaction at the parietal site (i.e., $\mathrm{Pz}), F(2,36)=$

$84.68, p<.05, \eta_{p}^{2}=.21$. High-alpha power increased from post-test to retention test in

9 members of the full vision group only $(p<.05)$. This resulted in significant between-group

10 difference in high-alpha power at retention test $(p<.05)$. There were no other group effects,

$11 F^{\prime} \mathrm{s}(1,18)=0.18-2.58, p^{\prime} \mathrm{s}=.13-.67, \eta_{p}{ }^{2} \mathrm{~s}=.01-.13$, or interaction effects, $F^{\prime} \mathrm{s}(2,36)=$

12

$0.16-1.89, p$ 's $=.18-.86, \eta_{p}{ }^{2} \mathrm{~s}=.01-.09$ 
a. $\mathrm{Fz}$

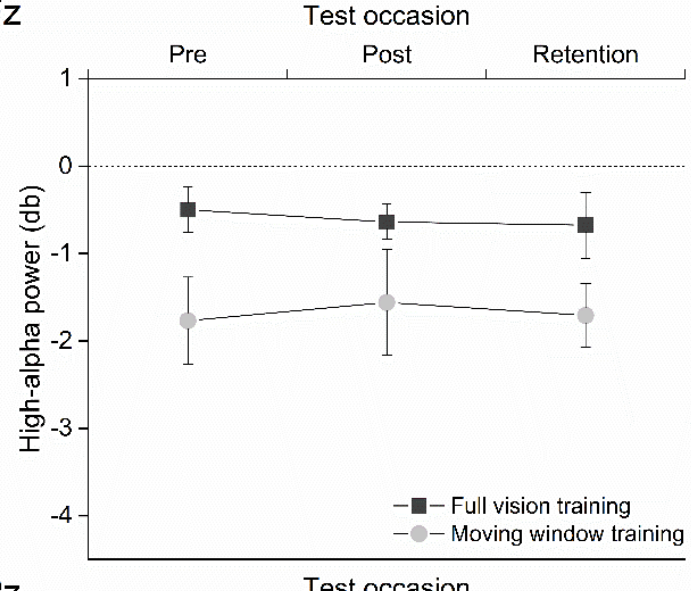

c. $\mathrm{Pz}$

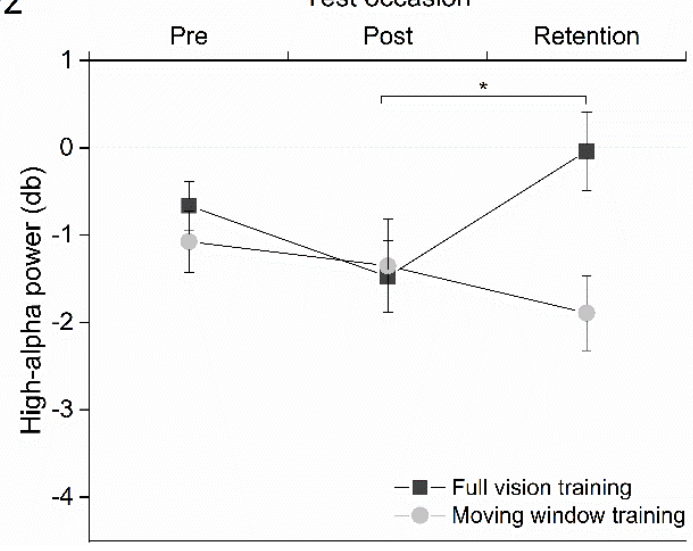

b. $\mathrm{Cz}$

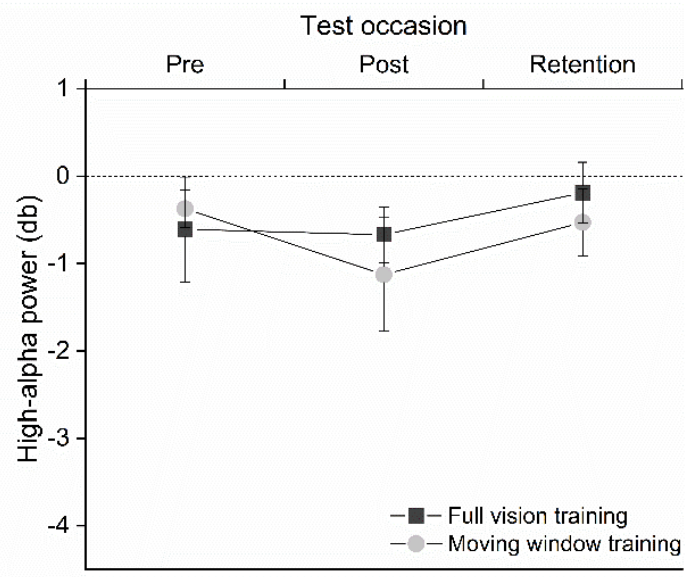

d. $\mathrm{Oz}$

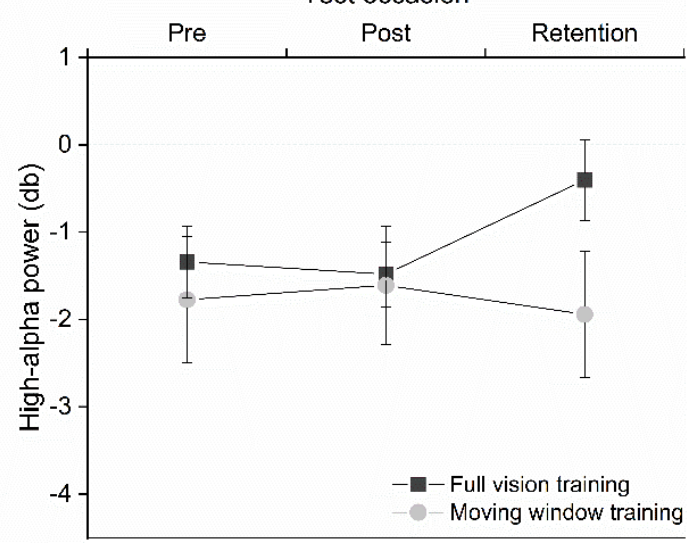

Figure 7. High-alpha power of the four regions in Experiment 2: (a) frontal (Fz), (b) central $(\mathrm{Cz}),(\mathrm{c})$ parietal $(\mathrm{Pz})$, and $(\mathrm{d})$ occipital $(\mathrm{Oz})$. Error bars indicate the standard error of the mean. Asterisk (c) indicates post-to-retention test difference $(p<.05)$ for the full vision training group only.

\subsection{Discussion}

In Experiment 2, we examined whether gaze-contingent training could enhance hazard perception of unlicensed trainee drivers by comparing two different training tools. The full vision training group watched all the video clips with unmanipulated vision during the training intervention whereas the moving window training group watched all the video clips with clear central and blurred peripheral vision during the training intervention. Before and after the training intervention, all the participants' hazard perception abilities were assessed at pre-test, post-test, and one month later in a retention test. 

moving window training group would show greater improvement in their skills than the full vision training group. The data did not reveal the expected group $\times$ test interactions. There was, however, a group main effect indicating that the moving window group performed better than their full vision counterparts. Closer inspection of each group indicated that the moving window training group improved their hazard discrimination from pre-test to post-test to retention test while the hazard discrimination scores of the full vision training group remained stable ${ }^{6}$ (Figure 6a). The training protocols did not influence hazard detection time. It is possible that training protocols of this nature first influence spatial perception, and may require more extensive training to deliver temporal perception benefits (see also Ryu et al., 2016). In sum, the results provide limited support for the primary performance-orientated hypothesis.

Our second hypothesis was that moving window training would encourage line-ofgaze and attention to align, and we tested this prediction by measuring EEG high-alpha power. Our hypothesis was partially supported. Specifically, members of the moving window training group tended to display less high-alpha power, reflecting increased cortical activation, at post-training retention, compared to their full vision trained counterparts. Importantly, high-alpha power increased from post-test to retention test at the parietal electrode for members of the full vision training group. Since parieto-occipital brain areas are important for the integration of visual and sensorimotor information (Ashe et al., 2006) it seems that the full vision group was less adept at integrating key visual information than the moving window group in the retention test.

\footnotetext{
${ }^{6}$ Readers should interpret these latter results with a degree of caution, as they represent planned follow-up tests of a non-significant group $\times$ test interaction.
} 
In conclusion, the results of Experiment 2 suggest that blurred peripheral vision training may yield subtle benefits in hazard perception skill by increasing attention and improving information pick-up from central vision.

\section{General Discussion}

The main objectives of the two experiments reported in this paper were to examine (i) the roles of central and peripheral vision in hazard detection as a function of driving experience; and (ii) whether perceptual training via the gaze-contingent paradigm can enhance hazard perception skill. The evidence accumulated from the two experiments provide several new mechanistic insights regarding driving hazard perception and how this can be developed.

\subsection{The importance of central vision in driving}

A first key finding is the importance of central vision for hazard detection. In earlier studies using the gaze-contingent display paradigm, experienced sport performers outperformed novices in both moving window and moving mask viewing conditions (Ryu et al., 2015; Ryu, Abernethy, Mann, Poolton, \& Gorman, 2013). This shows that experienced performers were superior at using both central and peripheral vision when compared to beginners. When central vision was removed, the experienced players were able to maintain reasonable performance by using the foveal gaze as an anchor point and monitoring the movement of players using peripheral vision (Ripoll, 1991). In driving, however, such a strategy might be difficult. In Experiment 1, hazard perception performance of both experienced and inexperienced drivers deteriorated significantly when central vision information was impaired. Although both driving and sport are dynamic visual environments, a key difference is that in sports such as basketball, players move their body and head to navigate the space around them, in response to the movement of other players and the ball. When driving a car, the body and head are fairly stationary in comparison, and this stationarity combined with the generally linear nature of driving could dampen the importance of peripheral vision. 
1 This observation is important since it was previously assumed that both central and peripheral

2 vision were of critical importance to skilled driving when driving a car (Chapman \&

3 Underwood, 1998; Crundall et al., 1999). Previous studies, however, did not measure

4 peripheral vision directly. The utility of peripheral vision in driving has also been questioned

5 by another recent study showing that drivers' performance was significantly impaired when

6 they were asked to fixate their central vision on a smartphone inside the car, and thereby rely

7 on peripheral vision for driving (Wolfe \& Rosenholtz, 2019). In brief, our findings imply that

8 drivers require their attention to be aligned with their central vision to detect hazards and

9 maintain safe driving. However, it is important to note that peripheral vision may be more

10 important than our current results imply when in real driving scenarios containing wider

11 fields of view and objects moving in three-dimensional space. Direct tests of the roles of central and peripheral vision in real driving should be conducted by future research (Crundall et al., 1999, 2002).

\subsection{The alignment of gaze and attention}

It has been argued that a limitation of gaze measurement systems that track only the line-ofgaze is that they cannot evidence that attention is extracted from the points of fixation (see Ryu et al., 2013). For example, knowing the line-of-gaze does not tell us whether the person's attention is allocated centrally around the line-of-gaze or if the line-of-gaze is simply a convenient anchor point from which to extract information from the peripheral vision (Findlay, 1982; Ripoll, 1991; Zelinsky, Rao, Hayhoe, \& Ballard, 1997). The findings of both our experiments provide evidence that moving window viewing encourages attention and line-of-gaze to align. In Experiment 1, we observed longer fixation durations, shorter saccadic amplitudes (Bertera \& Rayner, 2000; Cornelissen, Bruin, \& Kooijman, 2005; Loschky \& McConkie, 2000, 2002; Nuthmann, 2014; Ryu et al., 2015; Ryu et al., 2016) and more intense cortical activity at frontal and central sites in the moving window condition. The 
1 moving window condition also supported performance levels that were superior to the

2 moving mask condition and equivalent to the full vision condition. In Experiment 2, hazard

3 discrimination was superior at post-test and retention test in the group that received moving

4 window training. This was again endorsed by the EEG data providing some evidence of more

5 intense cortical activation at the post-training retention in members of the moving window

6 training group. There were no differences in the visual search strategies adopted by the

7 participants who had undergone the moving window versus those who had undergone the full

8 vision training in Experiment 2. This is consistent with a previous study that used a similar

9 training paradigm in expert decision making (Ryu et al., 2016). It provides good evidence that

10 the effects of moving window training are underpinned by more optimal neurophysiological

11 patterns of attention, rather than anything related to visual search strategies.

\subsection{A new approach to assess and develop hazard perception ability}

Moving window training is by no means the first training intervention designed to improve driving hazard perception. Other well-used approaches include pausing video clips and asking the driver to predict what would happen next (McKenna \& Crick, 1994), instructing beginner drivers where to look in order to identify hazards (Chapman, Underwood, \& Roberts, 2002), asking inexperienced drivers to place markers on potential hazard locations (Pollatsek, Narayanaan, Pradhan, \& Fisher, 2006), and by using commentary driving (Crundall, Andrews, van Loon, \& Chapman, 2010). The results of these studies are encouraging insofar as they reveal an increase in the ability to detect risk/hazard. However, despite these existing approaches, poor hazard perception remains a problem for inexperienced drivers. Our moving window training intervention, which operates in a less explicit manner than other methods, could provide an important step forward. Our findings have the potential not only to benefit new drivers, but also to improve current hazard perception driving tests. The current driving hazard perception test was developed based on 
1 the earlier studies (1960s and 70s; see for a discussion, Crundall, 2016; see also, Pelz \&

2 Krupat, 1974) where it was simply reasoned that safer driving is associated with earlier detection of hazards. Our findings demonstrate that there is more to hazard perception than simply hazard detection time. In fact, hazard detection time was our least sensitive measure of performance - in Experiment 2 this measure did not change over the course of our training intervention, nor did not distinguish the two training groups. It is possible that our gazetraining intervention facilitates the stimulus identification and decision-making components of information processing (i.e., stages that regulate response accuracy) more than the stimulus detection component (i.e., a stage that concerns detection speed). Employing a range of performance measures related to both speed and accuracy would provide a more comprehensive assessment of the various components of hazard perception and improve the current driving hazard perception test.

\subsection{Limitations and future directions}

While we sometimes refer to driving safety and accident risk, we should be careful to point out that the current experiments did not assess driving, they simply assessed hazard perception via computer-based video tests. We scaled our videos to simulate real driving by scaling the visual angle of the screen, but we acknowledge that the inability to replicate the wider field of view (e.g., awareness of stimuli in side windows and wing mirrors) and the three dimensional perspective of real driving is a limitation of screen-based studies. It should also be noted that most of our hazard events were towards the centre of the screen, at least for the final part of the hazard window, due to hazards that exit from the side being difficult to represent in two-dimensional screen-based viewing. This might contribute to the seemingly high importance of central vision for hazard perception in the current experiments. The importance of peripheral vision may be higher for real driving than we have detected here (Shahar et al., 2010). The extent to which our findings generalize to real driving is something 
1 that can be explored by future research. Future research could also further develop the

2 measures of hazard perception. We decided to improve our hazard discrimination measure

3 after conducting Experiment 1, and we switched to a more sensitive scoring metric in

4 Experiment 2. Future studies wishing to develop metrics even further could introduce

5 ambiguity zones around the perimeter of hazards to more precisely characterise varying

6 levels of response accuracy rather than adopting leniency via oversized hazard zones as we

7 did here (e.g., Wetton, Hill, \& Horswill, 2011).

While the technology is not currently able to provide gaze-contingent training in a live driving scenario, we foresee smart windscreen technology or smart contact lenses as ways to incorporate this paradigm into real driving soon. It should be noted that this limitation of our research applies to all research concerning the driving hazard perception test, and it even applies to the hazard perception test itself. The extent to which performance on screen-based tests predicts real-life driving safety remains a source of debate. Nonetheless, given that governments around the world enforce that learner drivers pass a hazard perception test before securing their driving license, there is an assumption that results on this test correspond to one's capacity to be a safe driver.

\section{Conclusion}

Across two experiments, we used a gaze-contingent display paradigm to examine the roles of central and peripheral vision and to determine whether perceptual training can enhance hazard perception skill. The findings highlight that (i) information from central vision is more important, at least for screen-based hazard perception tests, than information from peripheral vision in detecting hazards, (ii) clear central and blurred peripheral vision viewing helps to align line-of-gaze and attention, and (iii) training with clear central and blurred peripheral vision may provide some benefits above those yielded by full vision training to improve screen-based hazard perception ability. These results could have many implications for road 
1 safety. For example, our findings would caution against the development of in-vehicle

2 technology (e.g., smartphones, navigation systems) that may divert central vision away from

3 the road. Importantly, our findings provide a new perceptual training paradigm which could

4 improve hazard perception in dynamic activities such as driving.

5

6

7

8

9

10

11

\section{Acknowledgements}

12 We thank Imagitech Ltd., UK for providing the test stimuli and for helping with the selection 13 of the training stimuli. 


\section{References}

Adrian, E. D., \& Matthews, B. H. (1934). The Berger rhythm: potential changed from the occipital lobes in man. Brain, 57(4), 355-385.

Ashe, J., Lungu, O. V., Basford, A. T., \& Lu, X. (2006). Cortical control of motor sequences. Current Opinion in Neurobiology, 16(2), 213-221. doi:10.1016/j.conb.2006.03.008

Ball, K., Beard, B. L., Roenker, D. L., Miller, R. L., \& Griggs, D. S. (1988). Age and visual search: Expanding the useful field of view. Journal of the Optical Society of America, 5(12), 2210-2219. doi:10.1364/JOSAA.5.002210

Ball, K., Owsley, C., Sloane, M. E., Roenker, D. L., \& Bruni, J. R. (1993). Visual attention problems as a predictor of vehicle crashes in older drivers. Investigative Ophthalmology \& Visual Science, 34(11), 3110-3123.

Bertera, J. H., \& Rayner, K. (2000). Eye movements and the span of the effective stimulus in visual search. Perception \& Psychophysics, 62(3), 576-585. doi:10.3758/bf03212109

Chapman, P., \& Underwood, G. (1998). Visual search of driving situations: Danger and experience. Perception, 27(8), 951-964. doi:10.1068/p270951

Chapman, P., Underwood, G., \& Roberts, K. (2002). Visual search patterns in trained and untrained novice drivers. Transportation Research Part F: Traffic Psychology and Behaviour, 5(2), 157-167. doi:10.1016/S1369-8478(02)00014-1

Chaumon, M., Bishop, D. V. M., \& Busch, N. A. (2015). A practical guide to the selection of independent components of the electroencephalogram for artifact correction. Journal of Neuroscience Methods, 250, 47-63. doi:10.1016/j.jneumeth.2015.02.025

Cohen, J. (1992). A power primer. Psychological Bulletin, 112(1), 155-159. doi:10.1037/0033-2909.112.1.155

Cooke, A., Gallicchio, G., Kavussanu, M., Willoughby, A., McIntyre, D., \& Ring, C. (2015). Premovement high-alpha power is modulated by previous movement errors: Indirect 
evidence to endorse high-alpha power as a marker of resource allocation during motor programming. Psychophysiology, 52(7), 977-981. doi:10.1111/psyp.12414

Cornelissen, F. W., Bruin, K. J., \& Kooijman, A. C. (2005). The influence of artificial scotomas on eye movements during visual search. Optometry and Vision Science, 82(1), 27-35. doi:10.1097/01.OPX.0000150250.14720.C5

Crundall, D. (2016). Hazard prediction discriminates between novice and experienced drivers. Accident Analysis \& Prevention, 86, 47-58. doi:10.1016/j.aap.2015.10.006

Crundall, D., Andrews, B., van Loon, E., \& Chapman, P. (2010). Commentary training improves responsiveness to hazards in a driving simulator. Accident Analysis \& Prevention, 42(6), 2117-2124. doi:10.1016/j.aap.2010.07.001

Crundall, D., Underwood, G., \& Chapman, P. (1999). Driving experience and the functional field of view. Perception, 28(9), 1075-1087. doi:10.1068/p2894

Crundall, D., Underwood, G., \& Chapman, P. (2002). Attending to the peripheral world while driving. Applied Cognitive Psychology, 16(4), 459-475. doi:10.1002/acp.806

Delorme, A., \& Makeig, S. (2004). EEGLAB: an open source toolbox for analysis of singletrial EEG dynamics including independent component analysis. Journal of Neuroscience Methods, 134(1), 9-21. doi:10.1016/j.jneumeth.2003.10.009

Faul, F., Erdfelder, E., Buchner, A., \& Lang, A. (2013). G* Power Version 3.1. 7 [computer software].

Findlay, J. M. (1982). Global visual processing for saccadic eye movements. Vision Research, 22(8), 1033-1045. doi:10.1016/0042-6989(82)90040-2

Horswill, M. S., \& McKenna, F. P. (2004). Drivers' hazard perception ability: Situation awareness on the road. In S. Banbury \& S. Tremblay (Eds.), A cognitive approach to situation awareness: Theory and application (pp. 155-175). Aldershot: Ashgate. 
1 Huisingh, C., McGwin, G., Wood, J., \& Owsley, C. (2015). The driving visual field and a history of motor vehicle collision involvement in older drivers: A population-based examination. Investigative Ophthalmology \& Visual Science, 56(1), 132-138. doi:10.1167/iovs.14-15194

Jasper, H. (1958). The ten-twenty electrode system of the International Federation. Electroencephalography and Clinical Neurophysiology, 10, 370-375.

Klimesch, W. (2012). Alpha-band oscillations, attention, and controlled access to stored information. Trends in Cognitive Sciences, 16(12), 606-617. doi:10.1016/j.tics.2012.10.007

Land, M. F., \& Horwood, J. (1995). Which parts of the road guide steering? Nature, 377(6547), 339-340. doi:10.1038/377339a0

Lopez-Calderon, J., \& Luck, S. J. (2014). ERPLAB: an open-source toolbox for the analysis of event-related potentials. Frontiers in Human Neuroscience, 8(213). doi:10.3389/fnhum.2014.00213

Loschky, L. C., \& McConkie, G. W. (2000). User performance with gaze contingent multiresolutional displays. In A. T. Duchowski (Ed.), Proceedings of the 2000 symposium on eye tracking research \& applications (pp. 97-103). Palm Beach, FL: ACM.

Loschky, L. C., \& McConkie, G. W. (2002). Investigating spatial vision and dynamic attentional selection using a gaze-contingent multiresolutional display. Journal of Experimental Psychology: Applied, 8(2), 99-117. doi:10.1037//1076-898x.8.2.99

Makeig, S., Bell, A. J., Jung, T. P., \& Sejnowski, T. J. (1966). Independent component analysis of electroencephalographic data. In D. Touretzky, Mozer, M., Hasselmo, M. (Ed.), Advances in Neural Information Processing Systems (pp. 145-151). Cambridge, MA: MIT Press. 
1 McConkie, G. W., \& Rayner, K. (1975). The span of the effective stimulus during a fixation in reading. Perception \& Psychophysics, 17(6), 578-586. doi:10.3758/BF03203972

McKenna, F. P., \& Crick, J. L. (1994). Hazard perception in drivers: A methodology for testing and training. TRL Contractor Report 313. Crowthorne, UK, Transport Research Laboratory.

McLean, I. M., Mueller, E., Buttery, R., \& Mackey, D. A. (2002). Visual field assessment and the Austroads driving standard. Clinical \& Experimental Ophthalmology, 30(1), 3-7. doi:10.1046/j.1442-9071.2002.00487.x

Mourant, R. R., \& Rockwell, T. H. (1972). Strategies of visual search by novice and experienced drivers. Human Factors: The Journal of the Human Factors and Ergonomics Society, 14(4), 325-335. doi:10.1177/001872087201400405

Nuthmann, A. (2014). How do the regions of the visual field contribute to object search in real-world scenes? Evidence from eye movements. Journal of Experimental Psychology: Human Perception and Performance, 40(1), 342-360. doi:10.1037/a0033854

Pelz, D. C., \& Krupat, E. (1974). Caution profile and driving record of undergraduate males. Accident Analysis \& Prevention, 6(1), 45-58. doi:10.1016/0001-4575(74)90015-3

Pollatsek, A., Narayanaan, V., Pradhan, A., \& Fisher, D. L. (2006). Using eye movements to evaluate a pc-based risk awareness and perception training program on a driving simulator. Human Factors: The Journal of the Human Factors and Ergonomics Society, 48(3), 447-464. doi:10.1518/001872006778606787

Pradhan, A. K., Hammel, K. R., DeRamus, R., Pollatsek, A., Noyce, D. A., \& Fisher, D. L. (2005). Using eye movements to evaluate effects of driver age on risk perception in a driving simulator. Human Factors: The Journal of the Human Factors and Ergonomics Society, 47(4), 840-852. doi:10.1518/001872005775570961 
1 Rayner, K. (1975). The perceptual span and peripheral cues in reading. Cognitive Psychology, 7(1), 65-81. doi:10.1016/0010-0285(75)90005-5

Reingold, E. M., Loschky, L. C., McConkie, G. W., \& Stampe, D. M. (2003). Gazecontingent multiresolutional displays: An integrative review. Human Factors: The Journal of the Human Factors and Ergonomics Society, 45(2), 307-328. doi:10.1518/hfes.45.2.307.27235

Ripoll, H. (1991). The understanding-acting process in sport: The relationship between the semantic and the sensorimotor visual function. International Journal of Sport Psychology, 22(3-4), 221-243.

Ryu, D., Abernethy, B., Mann, D. L., \& Poolton, J. M. (2015). The contributions of central and peripheral vision to expertise in basketball: How blur helps to provide a clearer picture. Journal of Experimental Psychology: Human Perception and Performance, 41(1), 167-185. doi:10.1037/a0038306

Ryu, D., Abernethy, B., Mann, D. L., Poolton, J. M., \& Gorman, A. D. (2013). The role of central and peripheral vision in expert decision making. Perception, 42(6), 591-607. doi:10.1068/p7487

Ryu, D., Mann, D. L., Abernethy, B., \& Poolton, J. M. (2016). Gaze-contingent training enhances perceptual skill acquisition. Journal of Vision, 16(2), 1-21. doi: $10.1167 / 16.2 .2$

Shahar, A., Alberti, C. F., Clarke, D., \& Crundall, D. (2010). Hazard perception as a function of target location and the field of view. Accident Analysis \& Prevention, 42(6), 15771584. doi:10.1016/j.aap.2010.03.016

Underwood, G., Crundall, D., \& Chapman, P. (2008). Driving. In F. T. Durso, R. Nickerson, S. Dumais, S. Lewandowsky, \& T. Perfect (Eds.), Handbook of applied cognition (second edition) (pp. 391-414). Hoboken, NJ: Wiley. 
1 van Diepen, P. M. J., Wampers, M., \& d'Ydewalle, G. (1998). Functional division of the visual field: Moving masks and moving windows. In G. Underwood (Ed.), Eye guidance in reading and scene perception (pp. 337-355). Oxford: Elsevier.

Vater, C., Kredel, R., \& Hossner, E.-J. (2016). Detecting single-target changes in multiple object tracking: The case of peripheral vision. Attention, Perception, \& Psychophysics, 78(4), 1004-1019. doi:10.3758/s13414-016-1078-7

Vater, C., Kredel, R., \& Hossner, E.-J. (2017). Detecting target changes in multiple object tracking with peripheral vision: More pronounced eccentricity effects for changes in form than in motion. Journal of Experimental Psychology: Human Perception and Performance, 43(5), 903-913. doi:10.1037/xhp0000376

Weltman, G., \& Egstrom, G. H. (1966). Perceptual narrowing in novice drivers. Human Factors: The Journal of the Human Factors and Ergonomics Society, 8(6), 499-506. doi: $10.1177 / 001872086600800604$

Wetton, M. A., Hill, A., \& Horswill, M. S. (2011). The development and validation of a hazard perception test for use in driver licensing. Accident Analysis \& Prevention, 43(5), 1759-1770. doi:10.1016/j.aap.2011.04.007

Wolfe, B. A., \& Rosenholtz, R. (2019). Why Uber drivers scare you: Detecting road hazards with peripheral vision. Journal of Vision, 19(10), 162c. doi:10.1167/19.10.162c

Wood, J. M., \& Troutbeck, R. (1992). Effect of restriction of the binocular visual field on driving performance. Ophthalmic and Physiological Optics, 12(3), 291-298. doi:10.1111/j.1475-1313.1992.tb00400.x

Zelinsky, G. J., Rao, R. P. N., Hayhoe, M. M., \& Ballard, D. H. (1997). Eye movements reveal the spatiotemporal dynamics of visual search. Psychological Science, 8(6), 448-453. doi:10.1111/j.1467-9280.1997.tb00459.x 


\section{Supplementary Material}

\section{Experiment 2}

\section{Results - Moving window condition}

4 Performance data

5 Hazard discrimination. In the moving window condition, there were significant main

6 effects for group, $F(1,18)=5.22, p<.05, \eta_{p}{ }^{2}=.23$, and test occasion, $F(2,36)=24.15, p$

$7<.001, \eta_{p}{ }^{2}=.57$. The moving window training group showed higher response accuracy than

8 the full vision training group. Hazard discrimination improved from pre-test to post-test ( $p$

$9<.001)$, but not from post-test to retention test $(p>.05)$. Finally, there was no interaction effect between group and test occasion, $F(2,36)=.61, p>.05, \eta_{p}^{2}=.03$.

Hazard detection time. ANOVAs failed to reveal any significant main effect for test occasion, $F(2,36)=1.49, p>.05, \eta_{p}^{2}=.08$. There was no main effect for group, $F(1,18)$ $=.85, p>.05, \eta_{p}^{2}=.05$. Finally, there was no significant training group and test occasion interaction, $F(2,36)=.08, p>.05, \eta_{p}^{2}<.01$.

\section{Gaze behaviour}

Mean fixation duration. The results for mean fixation duration showed no significant differences between the two training groups, $F(1,18)=.08, p>.05, \eta_{p}{ }^{2}<.001$. There was no main effect for test occasion, $F(1.47,26.39)=.27, p>.05, \eta_{p}{ }^{2}=.02$. Finally, there was no interaction effect between training group and test occasion, $F(1.47,26.39)=.32, p>.05, \eta_{p}{ }^{2}$ $=.02$.

Mean saccadic amplitude. There was a significant main effect for test occasion, $F(2,36)=$ $6.19, p<.01, \eta_{p}{ }^{2}=.23$. Saccadic amplitude was increased after the training intervention in post $(p<.05)$ and retention $(p<.05)$ tests when compared to pre-test. There was no 
1 difference between the two training groups, $F(1,18)=.34, p>.05, \eta_{p}{ }^{2}=.02$, and no

2 interaction between training group and test occasion, $F(2,36)=.82, p>.05, \eta_{p}{ }^{2}=.04$.

3 Time difference between hazard start and first fixation onset time on hazards. There

$4 \quad$ was a main effect for test occasion, $F(2,36)=7.71, p<.01, \eta_{p}{ }^{2}=.30$. The first fixation on

5 hazards occurred more quickly after the training intervention at retention test than pre-test ( $p$

$6<.05)$ and post-test $(p<.05)$. However, there were no training group differences, $F(1,18)$

$7=.46, p>.05, \eta_{p}{ }^{2}=.03$, nor interaction between group and test occasion, $F(2,36)=.65, p$

$8>.05, \eta_{p}^{2}=.04$

\section{Cortical activity}

10 In the moving window condition, ANOVA revealed a significant main effect for test occasion

11 at $\mathrm{Pz}, F(2,36)=3.42, p<.05, \eta_{p}{ }^{2}=.16$, showing less high-alpha power after training

12 intervention at post-test $(p<.05)$ when compared to pre-test, but not at retention test ( $p$

$13>.05)$. High-alpha power was not different between post-test and retention test $(p>.05)$.

14 There were no main effects of test occasion at other sites, $F^{\prime} \mathrm{s}(2,36)=.10-2.17, p^{\prime} \mathrm{s}=.13$

$15-.83, \eta_{p}{ }^{2}$ 's $=.00-.11$. Further, there were no other group effects at any of the sites, $F$ 's $(1$,

$18)=0.49-2.38, p$ 's $=.14-.50, \eta_{p}{ }^{2}{ }^{\prime} \mathrm{s}=.03-.12$, or interaction effects, $F^{\prime} \mathrm{s}(2,36)=.45-$

17

$1.24, p ’ \mathrm{~s}=.30-.65, \eta_{p}^{2}{ }^{2} \mathrm{~s}=.02-.06$. 
Table S1. Mean $(S D)$ hazard discrimination and hazard detection time in the moving window condition for full vision training group and moving window training group in Experiment 2.

\begin{tabular}{|c|c|c|c|c|c|c|}
\hline \multirow{2}{*}{ Training group } & \multicolumn{3}{|c|}{ Hazard discrimination } & \multicolumn{3}{|c|}{ Hazard detection time } \\
\hline & Pre & Post & Retention & Pre & Post & Retention \\
\hline Full vision training & $\begin{array}{c}0.99 \\
(0.29)\end{array}$ & $\begin{array}{c}1.34 \\
(0.18)\end{array}$ & $\begin{array}{c}1.32 \\
(0.32)\end{array}$ & $\begin{array}{l}-2317.03 \\
(656.43)\end{array}$ & $\begin{array}{l}-2116.56 \\
(396.96)\end{array}$ & $\begin{array}{l}-2147.83 \\
(533.15)\end{array}$ \\
\hline $\begin{array}{l}\text { Moving window } \\
\text { training }\end{array}$ & $\begin{array}{c}1.15 \\
(0.19)\end{array}$ & $\begin{array}{c}1.64 \\
(0.30)\end{array}$ & $\begin{array}{c}1.59 \\
(0.40)\end{array}$ & $\begin{array}{l}-2438.46 \\
(364.61)\end{array}$ & $\begin{array}{l}-2270.20 \\
(490.22)\end{array}$ & $\begin{array}{l}-2355.54 \\
(376.03)\end{array}$ \\
\hline
\end{tabular}

Table S2. Mean $(S D)$ fixation duration, mean saccade amplitude, and time difference between hazard start and first fixation onset time on hazards in the moving window condition for full vision training group and moving window training group in Experiment 2.

\begin{tabular}{cccccccccc}
\hline \multirow{2}{*}{ Training group } & \multicolumn{3}{c}{ Mean fixation duration } & \multicolumn{3}{c}{ Mean saccadic amplitude } & \multicolumn{3}{c}{$\begin{array}{c}\text { Time difference between hazard start } \\
\text { and first fixation onset time on } \\
\text { hazards }\end{array}$} \\
\cline { 2 - 10 } & Pre & Post & Retention & Pre & Post & Retention & Pre & Post & Retention \\
\hline \multirow{2}{*}{$\begin{array}{c}\text { Full vision } \\
\text { training }\end{array}$} & 592.98 & 606.61 & 648.98 & 1.69 & 1.82 & 1.81 & 1525.05 & 1455.25 & 1175.23 \\
$(130.70)$ & $(150.86)$ & $(128.07)$ & $(0.29)$ & $(0.17)$ & $(0.25)$ & $(441.28)$ & $(438.15)$ & $(347.40)$ \\
\hline $\begin{array}{c}\text { Moving window } \\
\text { training }\end{array}$ & 633.27 & 653.19 & 685.33 & 1.68 & 1.97 & 1.93 & 1775.04 & 1462.45 & 1206.45 \\
& $(154.02)$ & $(148.41)$ & $(143.02)$ & $(0.46)$ & $(0.43)$ & $(0.51)$ & $(464.07)$ & $(397.19)$ & $(521.16)$ \\
\hline
\end{tabular}


Table S3. Mean $(S D)$ high-alpha power in the moving window condition in Experiment 2.

\begin{tabular}{|c|c|c|c|c|c|c|c|c|c|c|c|c|}
\hline \multirow{2}{*}{$\begin{array}{l}\text { Training } \\
\text { group }\end{array}$} & \multicolumn{3}{|c|}{$\mathrm{Fz}$} & \multicolumn{3}{|c|}{$\mathrm{Cz}$} & \multicolumn{3}{|c|}{$\mathrm{Pz}$} & \multicolumn{3}{|c|}{$\mathrm{Oz}$} \\
\hline & Pre & Post & Retention & Pre & Post & Retention & Pre & Post & Retention & Pre & Post & Retention \\
\hline $\begin{array}{c}\text { Full } \\
\text { vision } \\
\text { training }\end{array}$ & $\begin{array}{c}-1.53 \\
(1.49)\end{array}$ & $\begin{array}{c}-1.28 \\
(0.98)\end{array}$ & $\begin{array}{c}-1.43 \\
(1.66)\end{array}$ & $\begin{array}{c}-0.92 \\
(1.44)\end{array}$ & $\begin{array}{c}-0.60 \\
(1.42)\end{array}$ & $\begin{array}{c}-1.29 \\
(1.74)\end{array}$ & $\begin{array}{c}-0.17 \\
(1.22)\end{array}$ & $\begin{array}{c}-1.22 \\
(1.23)\end{array}$ & $\begin{array}{c}-0.79 \\
(1.71)\end{array}$ & $\begin{array}{c}-1.24 \\
(1.18)\end{array}$ & $\begin{array}{c}-2.00 \\
(1.61)\end{array}$ & $\begin{array}{c}-1.93 \\
(1.98)\end{array}$ \\
\hline $\begin{array}{l}\text { Moving } \\
\text { window } \\
\text { training }\end{array}$ & $\begin{array}{c}-1.47 \\
(1.84)\end{array}$ & $\begin{array}{l}-2.01 \\
(2.17)\end{array}$ & $\begin{array}{c}-1.93 \\
(1.28)\end{array}$ & $\begin{array}{c}-0.08 \\
(1.25)\end{array}$ & $\begin{array}{l}-0.46 \\
0.76)\end{array}$ & $\begin{array}{c}-0.61 \\
(0.83)\end{array}$ & $\begin{array}{c}-0.77 \\
(1.33)\end{array}$ & $\begin{array}{c}-1.09 \\
(0.99)\end{array}$ & $\begin{array}{c}-1.60 \\
(1.68)\end{array}$ & $\begin{array}{l}-2.02 \\
(1.77)\end{array}$ & $\begin{array}{l}-2.13 \\
(2.53)\end{array}$ & $\begin{array}{c}-2.68 \\
(2.43)\end{array}$ \\
\hline
\end{tabular}

